University of Massachusetts Amherst

ScholarWorks@UMass Amherst

Doctoral Dissertations 1896 - February 2014

$1-1-1959$

\title{
Mediating verbal responses and stimulus similarity as factors in conceptual naming by school-age children.
}

Harvey M. Lacey

University of Massachusetts Amherst

Follow this and additional works at: https://scholarworks.umass.edu/dissertations_1

\section{Recommended Citation}

Lacey, Harvey M., "Mediating verbal responses and stimulus similarity as factors in conceptual naming by school-age children." (1959). Doctoral Dissertations 1896 - February 2014. 1680.

https://doi.org/10.7275/qet1-3q93 https://scholarworks.umass.edu/dissertations_1/1680

This Open Access Dissertation is brought to you for free and open access by ScholarWorks@UMass Amherst. It has been accepted for inclusion in Doctoral Dissertations 1896 - February 2014 by an authorized administrator of ScholarWorks@UMass Amherst. For more information, please contact scholarworks@library.umass.edu. 


\section{MEDIATING VERBAL RESPONSES AND STIMULUS SIMILARITY AS FACTORS IN CONCEPTUAL NAMING BY SCHOOL-AGE CHLDREN}

LACEY - 1959 
MEDIATING VERBAL RESPONSES AND STIMULUS SIMILARITY AS FACTORS IN CONCEPTUAL NAMING BY SCHOOL-AGE CHILDREN

Harvey M. Lacey

Thesis Submitted in Partial Fulfillment of the Requirements for the Degree of Ph.D.

Un1 versity of Massachusetts, Amherst June, 1959 
TAELE OF CONTENTS

Page

ACKNOKLEDGMENTS. . . . . . . . . . . . . 111

INTRODUCTION . . . . . . . . . . . . . . 1

Practical Considerations. . . . . . . . . . 1

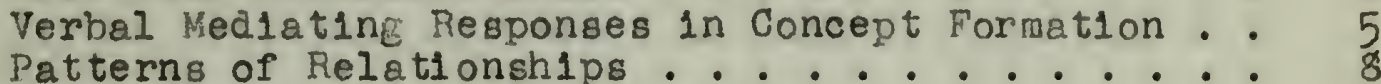

Predictions................. . . 10

Patterns $\mathrm{A}, \mathrm{B}, \mathrm{C}$, and $\mathrm{D}$ separately ...... 11

Compar1sons between and among Patterns

A, B, C, and D............. 14

METHOD . . . . . . . . . . . . . . 18

Deg1gn..................... 18

Hationale for control condition........ 18

Combination of conditions. . . . . . . . . 20

Stimul1 and Responses . . . . . . . . . . 22

Nonsense syllables............. 28

Apparatus. . . . . . . . . . . . 28

Procedure ................... 28

Familiarization with mediating regnonses.... 30

Trainin .................. 31

Fam1liarization with terminating responses... 32

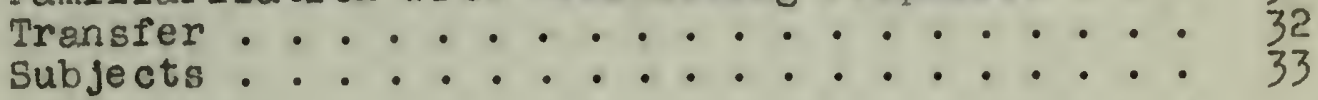

RESULTS. . . . . . . . . . . . . . 34

Training. . . . . . . . . . . . . . . 44

Transfer.

"Between 38 " for all Ss................. 45

Patterns $\bar{C}$ and $\bar{D}$. ............. . . 46

Patterns $\overline{\mathrm{A}}, \bar{B}, \overline{\mathrm{C}}$, and $\mathrm{D}$ separately ...... 47

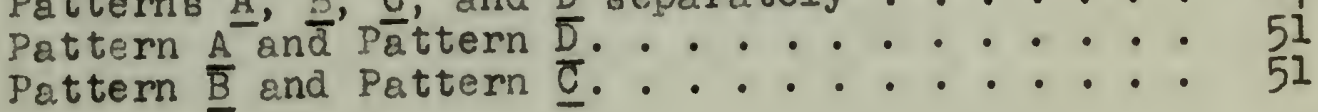


Page

DISCUSSION . . . . . . . . . . . . . 54

Patterns A, E, C, and D separately . . . . 55

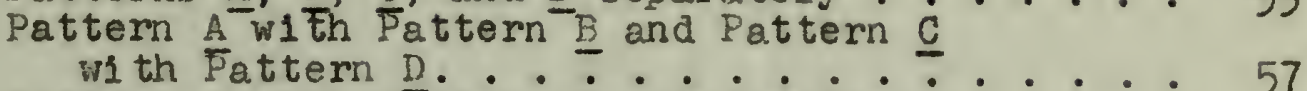

Pattern A with Pāttern $\underline{D}$ and Pattern $\underline{B}$

with Pattern $\mathrm{C} . . . . . . . . .58$

All 16 comblnations. . . . . . : : 59

SUMMARY. . . . . . . . . . . . . 61

REFERENCES . . . . . . . . . . . . 63

APPENDIX . . . . . . . . . . . . 66

Instructions for Training and Transfer phases. 66 


\section{ACKNOWLEDGMENTS}

I would like to express my appreciation to Drs. Goss, Kates, Neet and Wyman, whose assistance throughout the completion of this study is at this time gratefully acknowledged. A note of special thanks goes to Dr. Albert E. Goss who selflessly gave of his time, effort, and insplration without which this tudy would have indeed been imposstble.

I would also like to thank Dr. Trainor, Superintendent of The Erving School Union, who was most cooperative in allowing me to use the facilities of The Leverett School.

Lastly, I owe a special note of thanks to my wife, who assumed for herself the many tedlous chores w1 thout which this thesis would not have been completed. 


\section{INTRODUCTION}

The first objective of this study was to deternine the effects on conceptual naming of four patterns of relationships among line-drawing initiating stimul1, verbal medioting responses and stimul1, and verbal terminating responses. The second objective was to determine the effects on conceptual naming of two degrees of simllarity of the inltiating st1mul1. The third objective was to determine the joint effects on conceptual naming of the patterns of relationships and degree of similarity. Predictions concerning the direction and relative amounts of these effects for both degrees of similarity of the initlating stimuli are developed for each pattern separately and in relation to the others. Before these predictions are made, however, some extra-laboratory or practical conslaerations which served as the background of this study are noted. Then presented are some of the theoretical and related experimental materials concerning mediating responses in concept formation which influenced the more specific objectives and methods of this study. Also, since an understanding of the patterns of relationships is presupposed in the development of predictions, each of the four patterns is described alone with data on the role of two of them in generalization and discrimination.

Practical Considerations

Concept-formation task are tasks whose stimuli differ 
With respect to two or more dimensions or attributes such as helght and s1ze or a common form with different accompanying features. When each of the stimul1 is chosen or named by responding in terms of one or only some of the dimensions or attributes (e.E., he1ght; the common form) wh1le not responding in tems of the remaining attributes (e.8., s1ze, the different features) it is sald that a concept has been learned. Concepts then, are not entities but rather are such patterns of relationships between mult1-attribute st1mul1 and responses to those st1mul1. In conceptual naming the responses are verbal rather than motor.

The stimuli and stimulus-response relationships of many tasks differ from and are often more complicated than those of the precedins examples. However, such tasks can and do involve patterns of relationships among mult1-attribute st1mul1 and responses to those stimuli which can be labeled as concepts. For example, children are expected to learn that some older women are "aunts" whlle others are "not aunts." But chliaren must also learn that some aunts are "mother's sisters" whlle other aunts are "married to mother's brothers." In teaching children these responses, one might begin by training them to a1stingulsh between "aunts" and "not aunts" and then, when they have learned which older women are "aunts," teach them to discriminate between aunts who are "mother's sisters" and aunts who are "married to mother's brothers." 
The opposite sequence might also occur. After learning to label some older women as "mother's sisters" and others as "married to mother's brothers," chilaren might then be required to call both sets of older women "aunts."

Both sequences present problems for the chlla. In the Pirat case, after havine to learn to glve one name to those older women who are aunts, the child then has to give some of those women a second name which is different from the first and to give others of the aunts a still different name. The situation of the second sequence involves learning a common name (aunt) for two sets of adults whom the child has just learned to discriminate among as "mother's sisters" and "married to mother's brothers."

Relative similarity and dissimilarity of the older women In terms of appearance, manner and mode of dress must also be considered. Should all of the aunts be similar to each other and different from other older women in age, appearance, manner and mode of aress, the child might readly learn the common name "aunts," but, only w1th great difflculty, learn to discriminate between "mother's sisters" and "married to mother's brothers." Conversely, in addition to the aunts as a group alffering from other older women, should "mother's sisterg" differ from the "wives of mother's brotherg" in age, appearance, and mode of dress, alscriminating between the two sets might be relatively easy, while learning to call them by the common name "aunt" might be relatively more 
difflcult.

Similar problems arise in most areas of children's learning to label. Thus, while some furry animals are cats, they are also Slamese, Perslan, "Alley" end other kinds of cats. Among the other furry animals, different from cats, are dogs, which are Beagles, Collies, thoroughly bred, and other kinds. Other four-legged things, which have backs and arms but do not move, are chairs. There are also dining-room chairs, k1tchen chalrs, IIvine-room cha1rs, and "father's cha1r."

The relative ease w1 th which further common or different responses are conditioned to these sets of stimul1, as with the set of "aunt" st1mul1, might be influenced by prior acquisition of different or common responses, respectively. Felative similarity of the stimuli of the sets may also facilitate or retard acquisition of further responses.

Because the "aunts," "cats," "dogs," "cha1rs," and other sets of stinuli are initial cues for responses, such sets are called inftiating stimuli. Arousal of the common or different responses pirat conditioned to these initiating stimuli would produce stimuli which, in turn, might influence the conditioning of \& further common response or further different responses to the initiating stimuli. Hence these responses and stimul1, which right mediate between inltiating stimuli end the further responses, are labeled mediating responses and st1mul1. The further response or responses of 
these sequences are called terninating responses.

Within this classiflcation of actual and potential st1mul1 and responses of concept-formation tasks as in1tiating et1muI1, mediating responseg and st1mul1, and term1nating responses, the first of the sequences described above involves learning a common mediating responge (aunts) to different inflating stimuli which is followed by learning to respond to the same inlilating stimuli with different (or alscriminative) teminating regnonge日 (mother's sisters, marrled to mother's brothers). In the second sequence, learnin mediating discriminetive responses ("mother's s1sters," "married to mother's brothers") Is followed by learning e common terminating response ("zunts"). Verbal Mediatinf Fesponses in Concept Formation The significance for concept formation of verbal mediating responses or, more accurately, of patterns of relationshlps among inftiating stimul1, verbal mediating responses and stimuli, and verbal or motor terminating responses has been stressed in a number of recent theoretical analyses (Coss, 1957; Oegood, 1953; Spiker, 1956). Illustrative of such analysee is Osgood's statement that "It would seem that the only essent1al condition for concept formation is the learning of a common medating response (which is the mean1ng of the concept)..." (Osgood, 195j, p. 668). But investigation in which comon or discriminative verbal mediating responses were elther observed directly or established 
experimentally are of recent origin.

Baum (1951) found that ease of learning He1dbreder's object, form, and number concepts varied inversely with the number of alferent labels for successive instances of the sane concept. Fut she concluded that the number of $\underline{S} s$ and their protocois were not sufflcient for a rellable conclusion.

In the first of a series of studies enploying a modified Hanfnan and Kasinin (1942) block-sorting lask, Fenn and Goss (1957) Investigated trensfer to sorting by helght-size as a function of acquisition of comon nonsense-syllable or famil1er-word lavels for blocks within each of four helght-size categories. They hypothesized that acquisition of common labels for blocks within each of four helght-size categories would increase intra-category slinlarlty and decrease intercategory sinilarity of the block stimuli and thus fac1litate subsequent sorting by helght-size. As predicted, groups of matched normal adults and paranold schizophrenic adults who had Icarned to Iabel by height-size then sorted by height61ze more often than their controls. Corroborative findings with nursery school chliaren have been reported by Carey and Goss (1957). Further, Goss and Moylan (1958) demongtrated. that height-size placements increased with degree of mastery of nonsense-syllable and famillar-vord labels assigned in tems of helght-81ze. Finally, Lacey (1956) obtained direct relationghips between number of height-size placements and 
both number of labels and degree of mastery. Consistent with the se findings are those of Hunter and Ranken (1956) who found that $\underline{S} s$ who had previously labeled the midale two of six colors as e1ther "magenta" or "vermil1on" sorted the six stimuli in a manner congruent with the labeling responses. These studies are consistent in their suggestion that the occurrence or prior learning of verbal mediating responses fac1litates subsequent sorting of stimuli into conceptual categories. However, they have several 11mitations. F1rst, except for Baum (1951), who used Heldbreder's (1946a; 1946b) stimuli and nonsense-syllable responses, the stimuli employed have only been comblnations of physical dimensions and the terminating responses have only been motor cholces. Further, Carey and Goss (1957) excepted, the $\underline{S}$ save been adolescents or adults. Al though both response-mediated generalization and discrimination presumably contribute to concept formation, in no study has the design permitted separate assessment and comparison of the roles of the se two paradigms. Also, two other patterns of relationships among stimulus-response components of complex tasks, which are described below, have been completely 1gnored. Finally, in none of these studies of conceptual behavior has the effects of simllarlty of inltiating stimuli been assessed. These IIm1tations detemined the Ss, the nature of the stimul1, and the variables of the present study. F1rst, the inltiating stimul1 were more similar to pictorial 
representations of common objects and less readily concelved as comblnations of phyelcal dimensions. Second, the terminating responses were nonsense syllables. Third, the SE were ch1laren. Fourth, four paradigms of possible relationships among initiating stimuli, mediating stimuli and responses, and terminating responses were included; and the design provided for deternination of the1r separate effects as well as for comparisons of those effects. Finally, each of these four paradigms was comblined with two degrees of simllarity of Initiating st1muli.

Patterns of Relationships

F1g. I shows the four patterns of relationghips among Inltiating stimul1, mediating responses and stimul1, and terminating responses which were investigated in this study. Pattern A 18 the mechanism wh1ch Dollard and M1ler (1950) have labeled the acquired equivalence of cues or responsemediated generalization. In this pattern acquisition of a common verbal response to two or more initlating stimuli is followed by acquisition of a common terminating response.

Acquired distinctiveness of cues or response-mediated discrimination are the labels commonly applied to Pattern $\underline{B}$ (Dollard \& Miller, 1950; Goss, 1955). Highly dissimilar verbal mediating responses are learned to each of two or more initiating stimuli. Subsequently, discriminative terminating responses are conditioned to the inftiating stimuli to which the discriminative mediating responses were learned. 
A

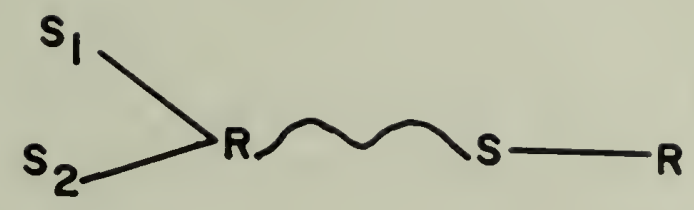

B.
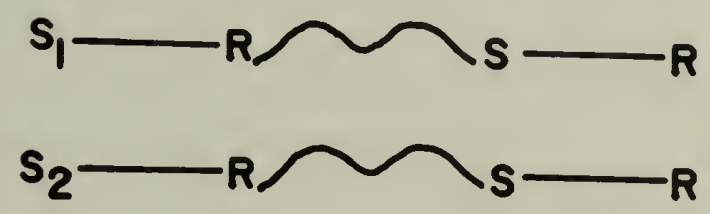

c.

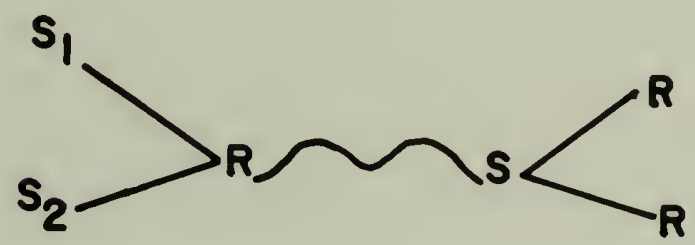

D

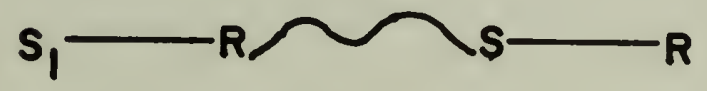<smiles>[R5]CCCCS[R]</smiles>

INITIATING

STIMULI

\section{MEDIATING RESPONSES}

AND
TERMINATING RESPONSES

\section{STIMULI}

F1g. 1. The four patterns of relationshlps among inltiating stimul1, common or alscriminative mediating responses and stimuli, and common or discriminative terminating responses. 
Positive transfer to the acquisition of comnon term1nating responses based on the acquired equivalence of cues has been demonstrated with relatively simple stimuli and stinulus-response relationships (e.g., B1rge, 1941; Grice, 1958; Jeffrey, 1953; Wurdock, 1952). Others (e.g., Goss \& Greenfeld, 1958; Grice, 1958; Splker, 1956) have reported that acquisition of discriminative verbal medating responses Pacilitates subsequent acquisition of discriminative teminating responses to relatively simple stimuli.

Although the existence of Patterns $\underline{C}$ and $\underline{D}$ has been noted previously (Goss, 1955) and these patterns were used in the preceding 11lustrations involving the naming of aunts, neither pattern has been included in prior investigations of effects of relationships involving mediating verbal responses. Pattern $\underline{C}$ is one in which a common response is first learned to two or more inlt1ating stimuli. Sg are then required to learn different terminating responses to each of the stimuli instead of learning a further common response as is the case for Pattern $\mathbb{A}$. In Pattern D, different verbal mediating responses are conditioned to initiating stimuli after which a common teminating response to those stimul11e strengthened. Predictions

Three sets of predictions were formulated regarding acquisition of common or discriminative verbal terminating responses under experimental conditions in which mediating responses and stimuli of Patterns $\underline{A}, \underline{B}, \underline{C}$, and $\underline{D}$ were 
expected to be present relative to sequisition of those ter minating responses under control conditions in which mediating responses and stimull were not expected to be present. (The exact procedure for the control condition is described in the section on "method.") The flrst set of predictions concern relative levels of mastery or rates of acquisition of terminating responses for each of the four patterns of relationships separately as functions of experimental and control conditions and of degree of simllarity of initiating stimuli.

Potterns A, E, C, and D separately.--In Pattern A, the experimental condition involved learning a common mediating response to two sets of in1tiating stimull after which a common terminating response was learnod to these same initiat1ng stimul1. Beoause the presence of mediting responses and Bt1rnul1 was expected to 1 ncrease the similarity of the initiating stimuli, it was predicted that the common terminating response woula be acquired more rapidiy under the experimental condition than under the control condition. Also, regardess of pretraining conditions, acquisition of the common teminating response was expected to be faster with similar initiating stimuli than with dsolmilar initiating stimuli. The basis for both predictions was the more general principle that interstimulus generalization of responses is directly related to similarity of initiating stimuli and of compounds of initiating and mediating stimuli (Dollara \& 
Miller, 1950; OBgood, 1953).

The presence of a cominon nediating stimulus might occasion an increase in the gimilarity of dissinilar stimuli different than the increase in the simplarity of alsairilar stimul1. If so, afferent amounts of facilitation should be obtalned with gimilar than with dissimilar initiating stimuli to occasion a significant interaction of control and experimental conditions with oimilor or dissimilar initiating stimul1. Present data and theorles, however, provided no satiafactory basis for the prediction of relatively greater faclitation either with similar or with alssimilar initiating stimuli.

In Pattern $\underline{B}$, discriminative mediating responseg were conditioned to the initiating atimuli after which discriminative teminating responses to those stimull vere learned. Accordingly, an experimental condition with alscriminative mediating responses and stimuli was expected to produce faster acquisition of discriminative terainating responses than the sontrol condition. Also, because rate of acquisition of alscriminative responses increases with alesimilarlty of st1ral1 (Dollard \& Miller, 1950; Osgood, 1953), faster leaming of discriminative terminating responses was predicted for dissinilar than for similar initiating stimuli. It might be assumed that stimuli resulting from dissimilar mediating responses produce a greater increase in the dissimilarity of similar than of dissimilar initiating 
stimul1. If so, acquisition of discriminative mediating responses should produce greater facilitation in the learning of discriminative terminating responses to similar than to dissimilar initiating stimuli.

Because the presence of the common mediating stimulus in Pattern $\underline{C}$ should increase the similarity of initiating stimul1, less rapla acquisition of discriminative terminating responses was expected under the experimental condition than under the control condition. Disregarding experimental and control conditions, faster acquisition of discriminative terminating responses was predicted for dissimilar than for similar initiating stimul1. Both predictions were based on the principle of a direct relationship between ease of learning discriminative responses and similarity of inltiating stimuli and of compounds of Inltiating and mediating stimuli (Dollard \& M1ller, 1950; Osgood, 1953).

As for Pattern $A$, the common mediating stimulus might occasion an increase in the similarity of similar initiating stimul1 different than the increase in the similarity of

1. Data bearing on this assumption for somewhat complex stimulus patterns involving two or more stimulus modalities (v1gual for flgure; proprioceptive, auditory for verbal response-produced stimul1) are, to the author's knowledge, nonexistent. Though the extension to the condition of this experiment is tenuous, this assumption is consistent with Miller's analysis of the effects on discrimination of multialmensional variations in tastes, colors, points, and tones in which he concluded "clearly, the addition of independentIy variable attributes to the stimulus increases the channel capacity, but at a decreasing rate" (M11ler, 1956, p. 88). 
diselmilar initiating stimuli and thus occasion differences In amounts of retardation relative to the control conditions. Again, however, avallable data and present theory do not warrant a specific prediction.

The different mediating stimuli of Pattern D presumably increased the dissimilarity of the initiating stimuli to which the common terminating response is to be learned. Accordingly, acquisition of the common teminating response was expected to be slower under the experimental than under the control condition. Because of the direct relationship between rate of acquisition of a common response and similarity of stimul1 (Dollard \& M11ler, 1950; Osgood, 1953),. faster learning of the common teminating response was expected with similor than with dissimilar inltiating stimuli. As for Pattern $\underline{B}$, it might be assumed that disimilar mediating stimul1 produce a greater increase in the dissimilarity of similar than of dissimilar initiating stimuli. Should this assumption be correct, acquisition of discriminative mediating responses should result in less retardation with aissimilar than with similar initiating stimuli.

Comparisons between and amonis Patterns $\underline{\mathrm{A}}$, $\underline{\mathrm{E}} \underline{\mathrm{C}}$, and $\underline{\mathrm{D}} \cdot--$ Pattern $\underline{A}$ and Pattern $\underline{D}$ both have a common terminating response but differ in that the former has a common mediating response while the latter has discriminative mediating responses. With elther similar or dissimilar initiating stimul1, 1t was predicted that the common terminating response 
would be acquired more rapialy with Pattern A than with Pattern D. This prediction follows from two earlier predictions of facliltation or positive transfer due to the common mediating response and stimulus of Pattern $A$ and of retardation or negative trangfer due to the discriminative mediating responses and stimull of Pattern $\underline{D}$.

While Pattern $\underline{E}$ and Pattern $\underline{C}$ have discriminative and common mediting responses, respectively, both have discriminative teminating responses. In Pattern $\underline{B}$, the presence of distinctive mediating stimuli was expected to facilitate acquisition of alscriminative terminating responses,

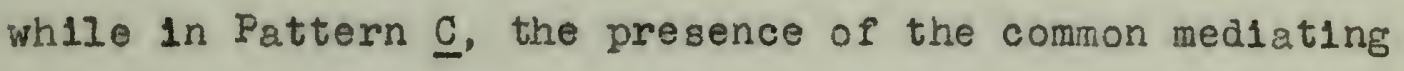
stimulus was expected to retard acquisition of discriminat1ve terminating responses. The prediction was, therefore, that, disregarding degree of similarity of stimul1, more correct discriminative teminating responses would be obtained with Pattern $\underline{B}$ than with Pattern $\underline{\mathrm{C}}$ under the exper1mental condition and across control and experimental conditions.

Lacey (1956) observed that rate of learning varied inversely with the number of responses for the conceptual naming of blocks. Though his inltiating stimuli and those of this study bear 11ttle resemblance, his finding provides some basis for predictions that, disregarding degree of similarity of the initiating stimuli, the common teminating response of Pattern $A$ and of Pattern $D$ should be acquired 
more rapidy than the alscriminative teminating responses of Pattern $\underline{B}$ and of Pattern $\underline{C}$, respectively. It follows, that more correct teminating responses shoula be obtained w1 th Patterns $\underline{A}$ and $D$ together than with Patterns $\underline{B}$ and $\underline{C}$ together. Further, because of the predictions that terminating responses should be acquired faster with similar than W1 th dissimilar stimuli for Pattern $A$ and the converse for Pattern $\underline{B}$, It was also expected that Patterns $\underline{A}$ and $\underline{B}$ would interact with degree of 8 imilarity. The predictions of faster acquisition of terminating responses with similar than with dissimilar stimuli for Pattern D and of the converse for Pattern $\underline{C}$, generated the prediction of an inter action of these patterns with degree of similarity.

For all 16 combinations of conditions, the most rapid learning was expected for pattern $\Lambda$ with similar initiating stimuli under the experimental condition. The slowest learning was expected for Pattern $\underline{C}$ with similar initiating stimuli under the experimental condition. Both predictions were based on the notion of similar initiating stimull made even more similar by a common mediating stimulus. For the former such great similarity should be facilitative, while for the latter it should be inhibitory. Performances of the remaining 14 combinations were of course expected to be between these extremes. Crders of performances within particular Eroups of some of the 14 combinations were predicted by the first two sets of hypotheses. A prediction of the order of 
211 14, however, could not be made with sufficlent bases or precision to warrant the attempt. 


\section{METHOD}

\section{Design}

Rationale for control condtion.--Previous work had indicated that the influence on transfer of the acquired equivalence and the acquired distinctiveness of cues must be assessed against controls for the effects of two factors Which are presumed to occur during the training phase of transfer studies and to then affect perfomance during the transfer phase (Goss, 1955; Coss \& Greenfeld, 1958; Sp1ker, 1956). One of these factors 18 warm up or learning set in the form of experlences such as familiarization with the conditions of stimulus presentation, with the palred-associates technique, and with the generel requirements of a concept formation task and, more speolfically, of both generalization and discrimination responses to initiating stimuli: The other factor 1s experience in orlenting to the common or distinctive featureg of the initiating stimuli which are relevant to formation of the concepts. Since neither factor is specific to the particular associations formed during training and transfer phases, they have been referred to as nonspecif1c bases of transfer (Osgood, 1953).

In this study the control for sny fac1litation of the acquisition of comon or discriminative terminating responses due to warm up was the use of a control condition in which common or discriminative responses were conditioned to sets 
of Initiatine stimuli which did not resemble the sets of inltioting stimuli of the transfer phase. Because features of the training and transfer phases other than the set of Inltiating stimul1 were the same, however, those experiences involved in werm up, other than specific associations between the inltiating stimuli and responses of the training phase, were expected to generalize from the training phase to the transfer phase. Because of alfferences in specific features as well as general characteristics of the sets of stimuli of the training and tronsfer phases, it was not expectea that specif1c responses would generalize from the former to the latter phase. Prior learning with sets of stimuli not resembling those of the transfer phase, therefore, provided for facilitation of the acquisition of common or discrimingt1ve terminating responses based on warm up or nonspec1f1c assoclations whlle it precluded the presence of speciflc associations involving cominon or discriminative mediating responses and etlinuli.

Fac1litation based on receptor-orienting responses was controlled by the use of two parallel sets of simllar initiating stimuli and two parallel sets of dissimilar initiating stinuli which required the same receptor-orienting responses. Thus, receptor-orienting responses to the set of stimull of the training phase and to the paraliel set of stimull of the transfer phase would be the same.under both experimental and control conditions. Because the stimull of the parallel 
similar and parallel dissimilar sets of stimuli differed with respect to the nature of the features to which the orlenting responses were made as well as in their general characteristics, no generalization of specific assoclations involving mediating responses and stimuli from training to transfer phases was expected.

Combinations of conditions.--Under the experimental condition each of the four patterns of relationships among initiating stimuli, mediating responses and stimuli, and termineting responses was combined with both similar and dissimilar initiating stimuli. Corresponding to each of these elght combinations was a control for the combined effects of nonspecific transfer and receptor-orienting responses. Thus, in all, there were 16 combinations of conditions.

For each combination of experimental or control conditions with similar or dissimilar initiating stimuli, each $\underline{\mathrm{S}}$ was administered both Pattern $\underline{A}$ and Pattern $\underline{B}$ or both Pattern $\underline{C}$ and Pattern $\underline{D}$. Because two patterns were administered to each $\underline{S}$, only elght rather than 16 separate groups were required to realize the 16 combinations of conditions.

There were two reasons for assigning two patterns to each S. One was that with only a limited number of gs avallable, administration of two patterns to the same $\underline{s}$ required half as many $\underline{S}$ s a design in which different Ss were assigned to each of the 16 combinations of conditions. More importantly, as shown in F1g. 2, by combining Pattern A with 
TRAINING

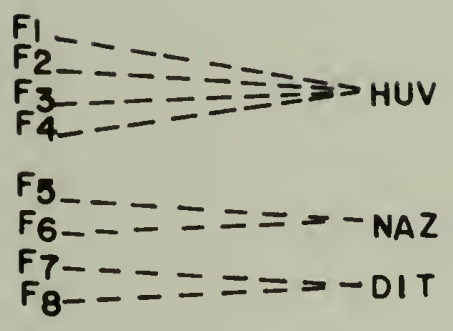

TRANSFER
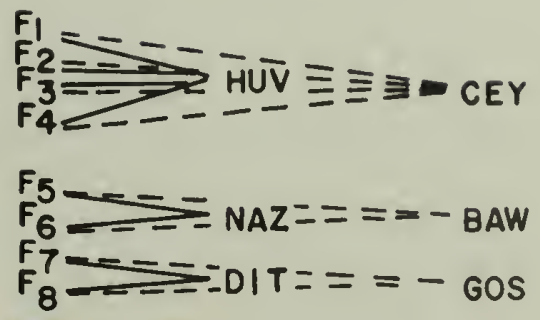

ASSIGNMENT TO $A$ and $B$

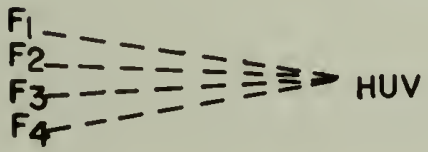

$$
\begin{aligned}
& F_{5}-ニ=ニ=-N A Z \\
& \mathrm{~F}_{\mathrm{B}}=ニ===- \text { - } 01 \mathrm{~T}
\end{aligned}
$$

ASSIGNMENT TO $C$ and $D$

$\begin{array}{ccccc}\text { INITIATING } & \text { MEDIATING } & \text { INITIATING } & \text { MEDIATING } & \text { TERMI- } \\ \text { STIMULI } & \text { RESPONSES } & \text { STIMULI } & \text { RESPONSES } & \text { NATING } \\ & \text { AND } & & \text { AND } & \text { RESPONSES } \\ & \text { STIMULI } & & \text { STIMULI } & \end{array}$

F1g. 2. The relationships among inltiating stimil, mediating responses and stimuli, and terminating respunses for assignment to Patterns $A$ and $\underline{B}$ or to Patterns $C$ and $D$ with similar or dissimilar face iñtlating stimul1. The relationsh1ps with house stimuli were the same. Under the experimental condition the inftiating stimuli of both the training phase were identical. Under the control condition the face or house initiating stimuli of the training phase were replaced by house or face stimuli, respectively, for the transfer phase. The broken lines indicate associations to be established and the solid IInes indicate already established associations. 
Pattern B and Pattern C w1th Pattern D, all Ss learned three responses to the inltiating stimuli of the training phase and three responses to the initiating stimuli of the transfer phase. Also, both the training and the transfer phases for all Ss then 1 nvolved leaming a. common response to one set of stimuli and discriminative responses to the other set of stimuli. Only by combining Pattern $\underline{A}$ with Pattern $\underline{B}$ and Pattern $\underline{C}$ with Pattern $\underline{D}$ was it possible to equalize the two phases in terns of numbers of responses $\underline{S} s$ were to learn and w1 th respect to acquisition of common and discriminative mediating as well as teminating responses.

St1mul1 and Fesponses

The stimuli were the four sets of elght line drawings of stylized faces or houses reproduced in FIgs. 3a, 3b, 3c, and 3a. In order to have an irrelevant dimension each of the eight drawings of each set was printed on blue, green, yellow, and pink pastel paper. Thus, there were 128 stimul1 in all. The 16 faces are all of the same s1ze as are the 16 houses. The area of the faces, excluding the hair, is essent1ally the same as the area of the houses, excluding the chimney and smoke.

The faces of one set (FIg. 3a) differ from each other with respect to direction and degree of curvature of the halr, eyes, and mouth. These faces are relatively more dissimilar than those of the other set (Fig. 3b) which differ Prom each other only with respect to direction and degree of 

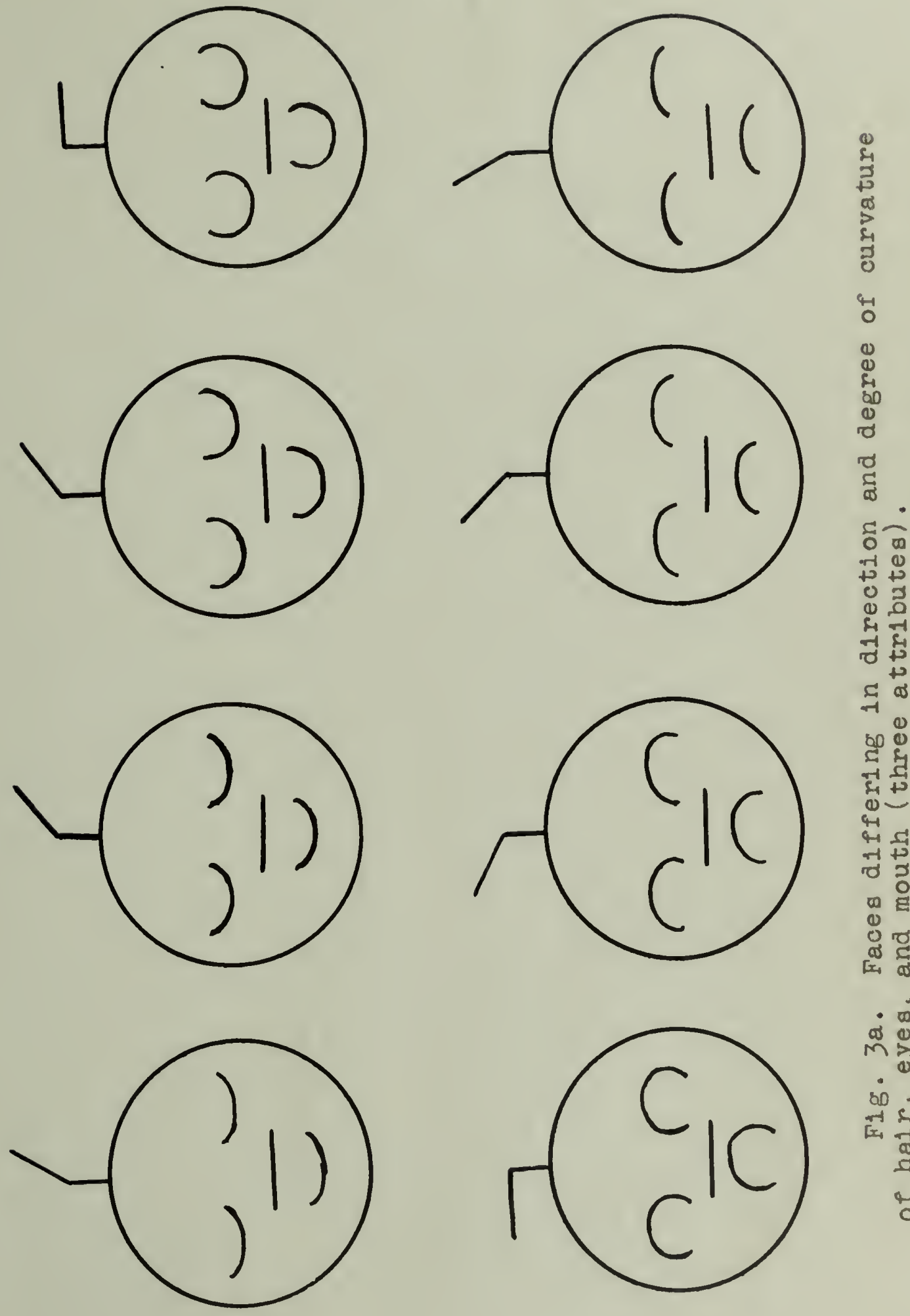

เ $m b$ की है 

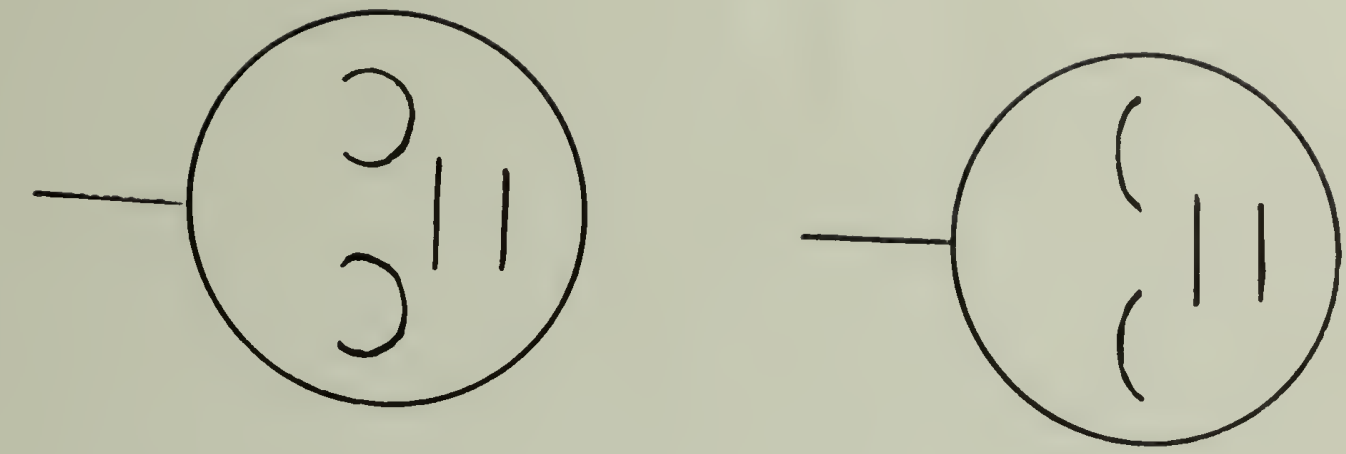

0
4
5
5
0
5
4
5
0
4
0
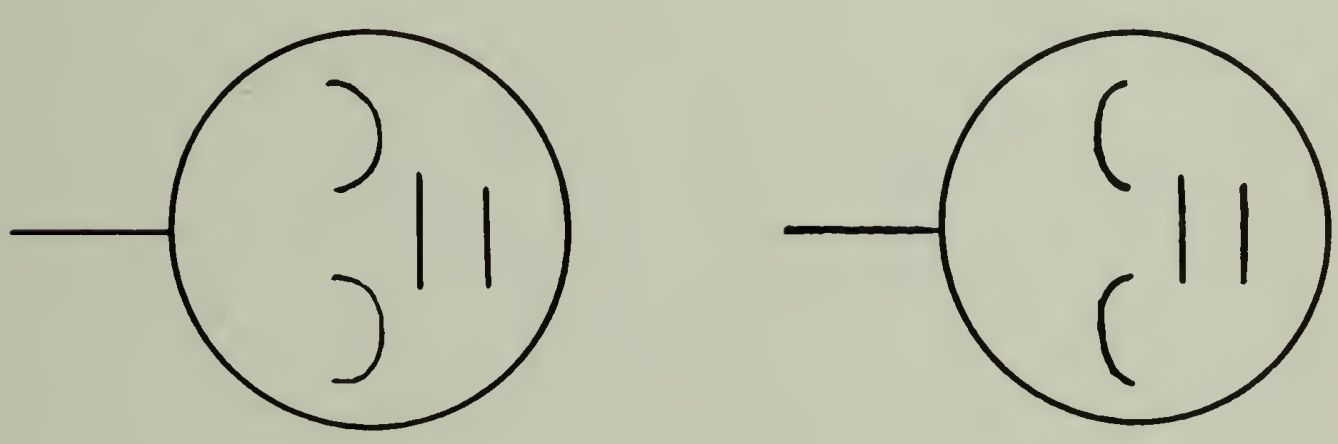

0
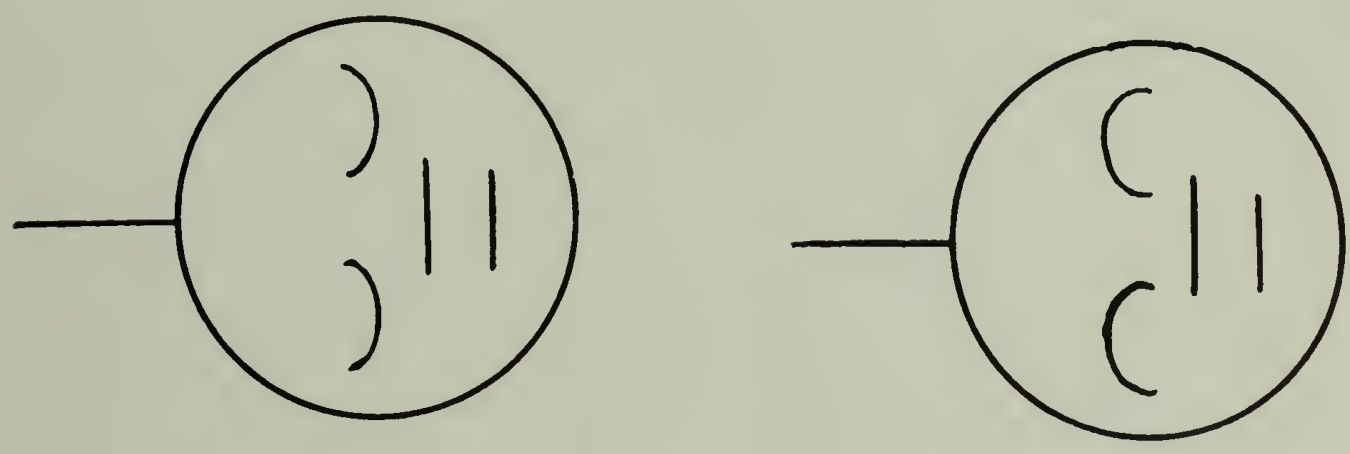

담
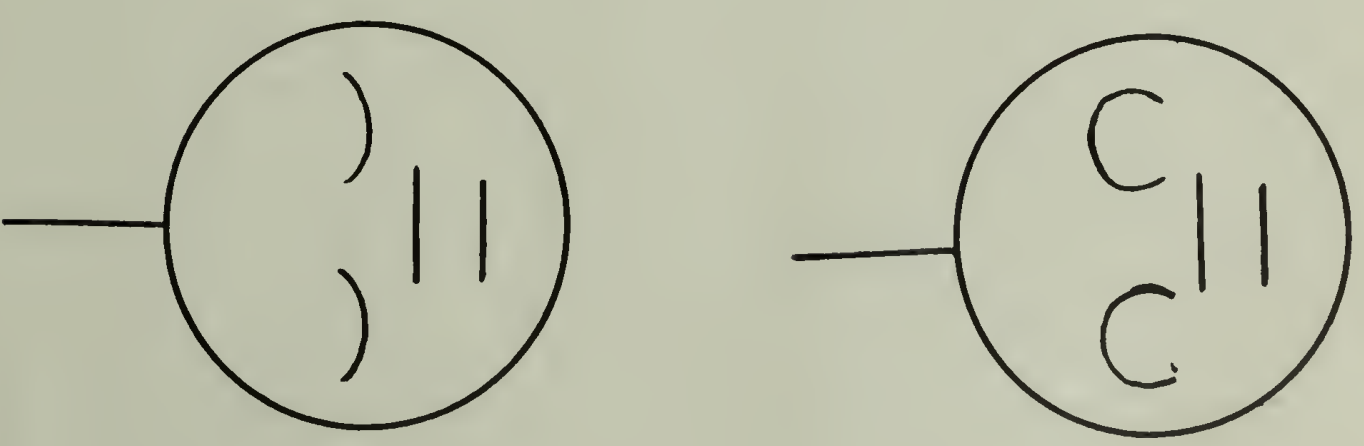

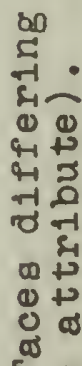

[I

m

-

तो

If

भ 

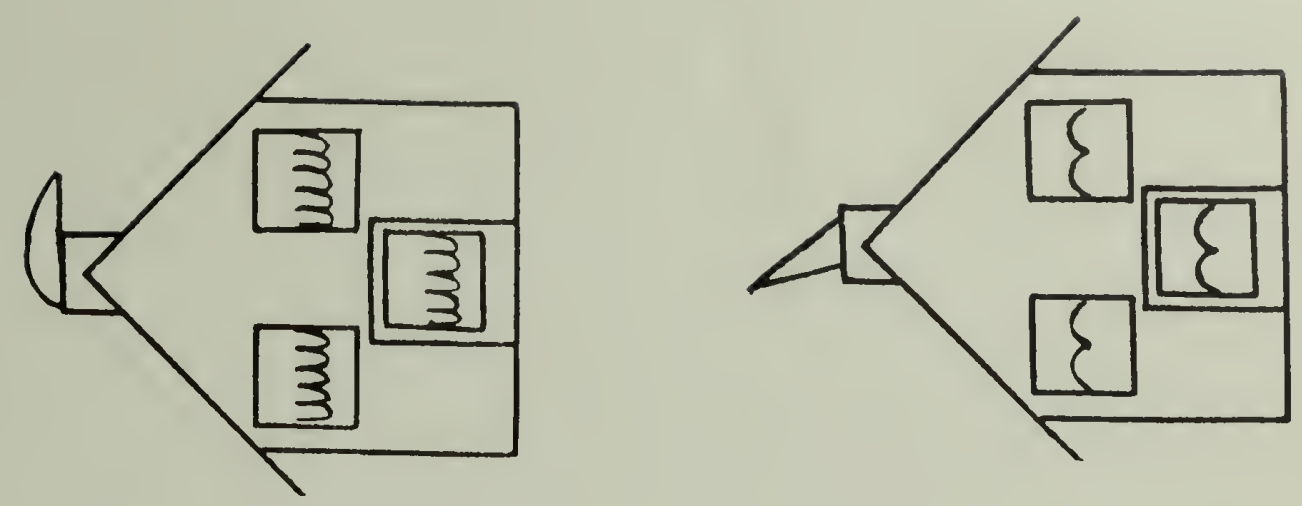

का कै क 30

(

$>C$

अ

$4 \frac{4}{3}$
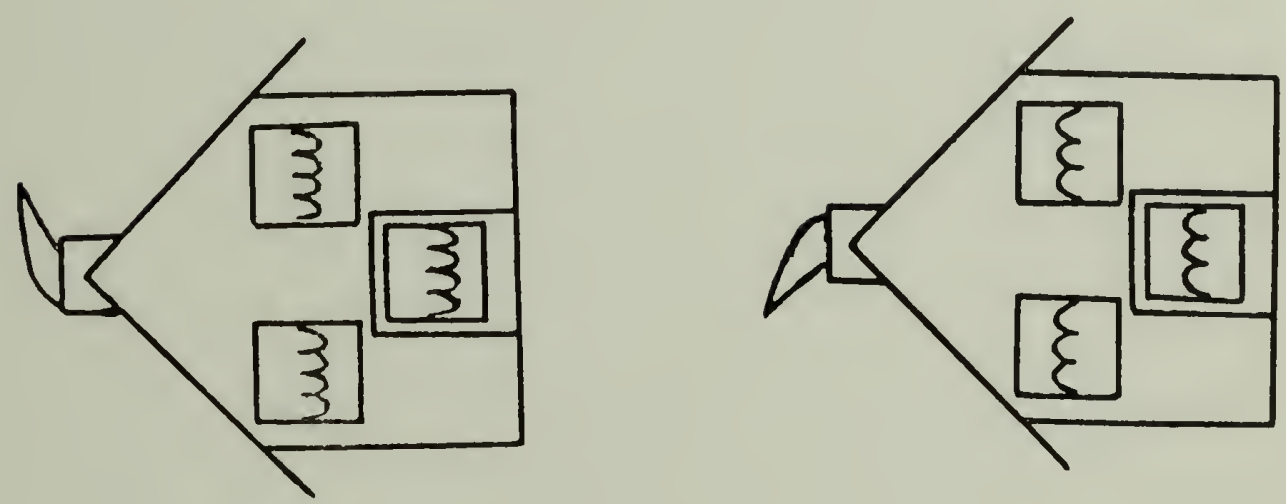

a 4

\& 0

\& 6

(1).

व 80

ช 0

เ

๙

c 0.

0 \&

नी

0 ๘

( 0

(4) 00

न 0

50 담
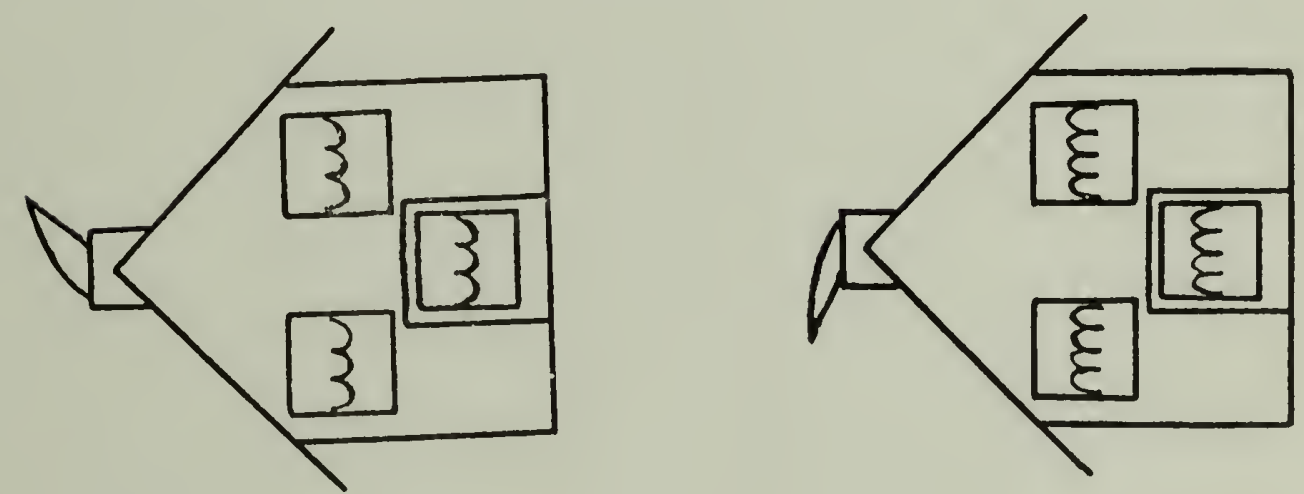

न 4 H

दी ह

-1 30

0 व

a d

क है भ

ना ळ 0

o

c)

क t

30 .

00 -
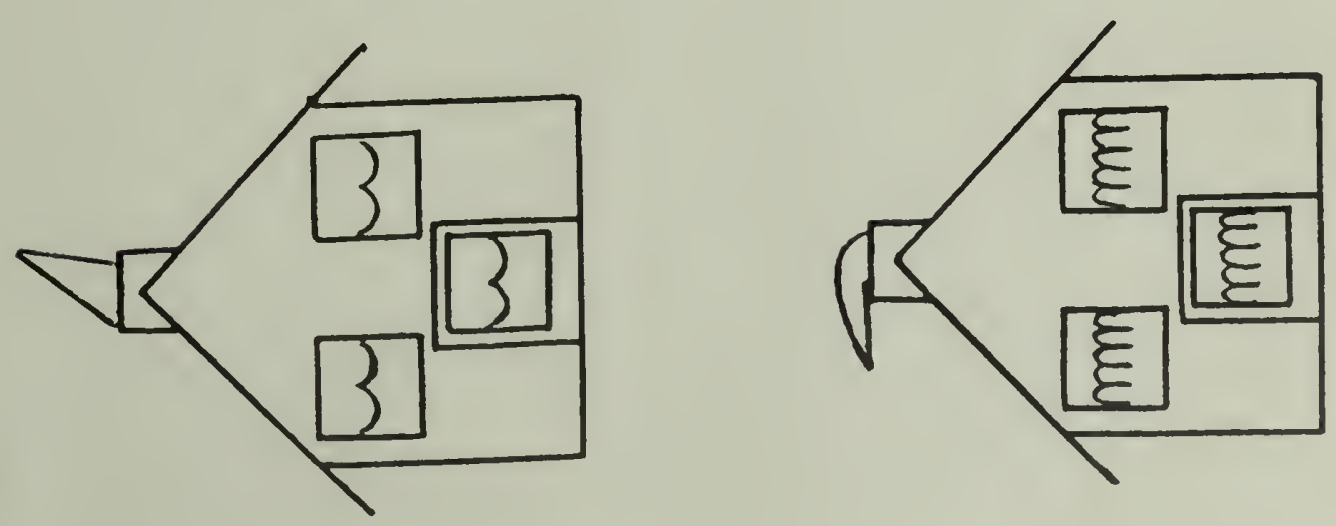

. 0

( )

Mना

- б

$80 \mathrm{C}$

-1

[r. 3 넝 0 

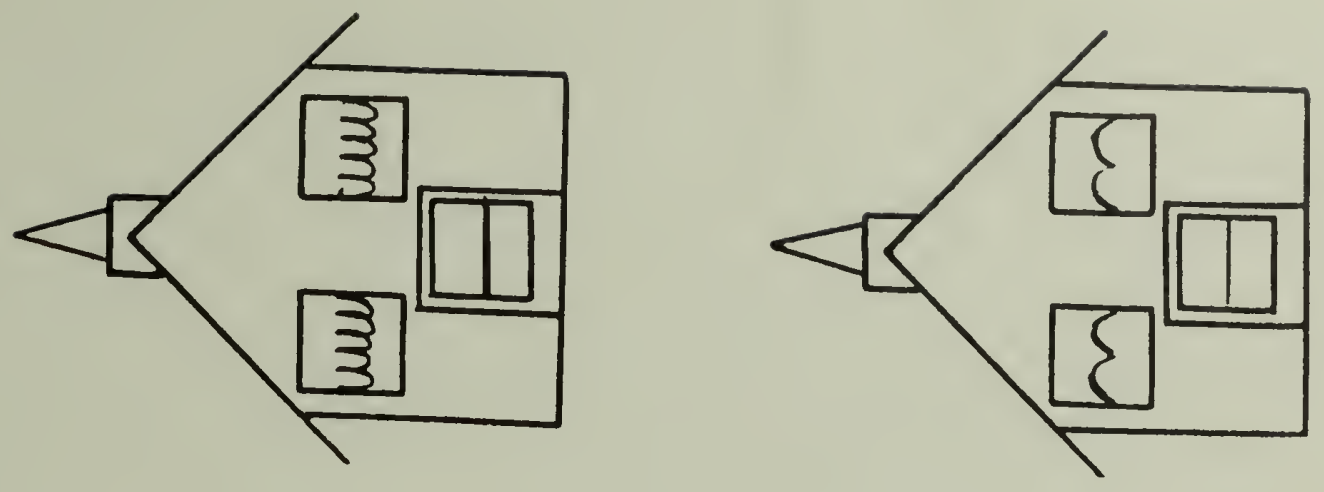

0
0
0
0
0
0
0
0
0
0
7
7
0
0
0
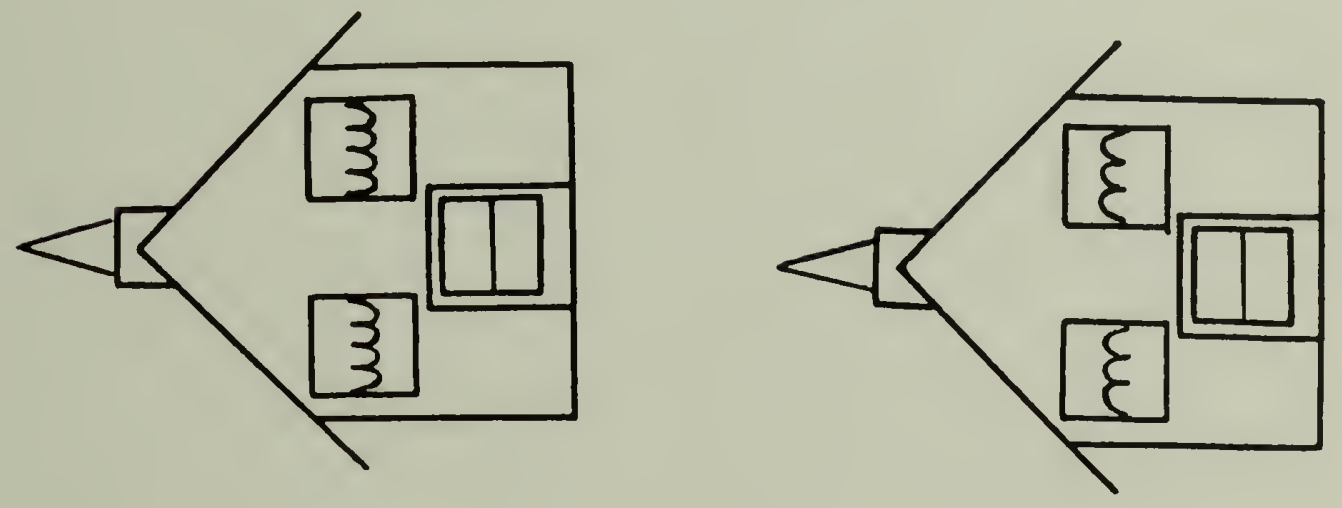

4
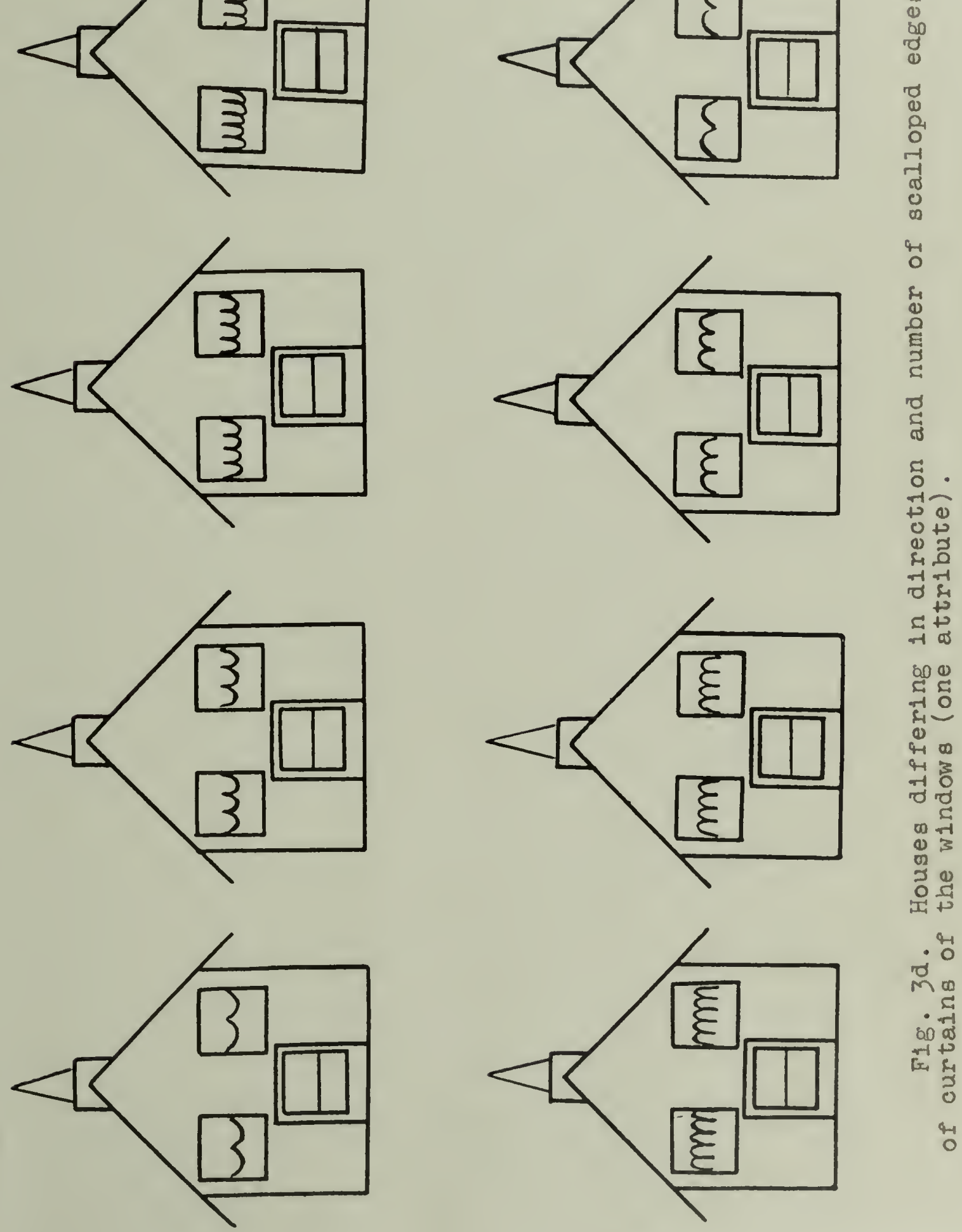
curvature of the eyes. The hair of all eight of the similar faces is a stralght Iine rising vertically from the center of the top of the head; the mouth is a horizontel ine.

The houses of one set ( $\mathrm{Fig}$. 3c) differ from each other with respect to direction and degree of curvature of the smoke from the ohlmney, and in number (five, four, three, two) and degree of curvature of the scalloped bottoms of the shades in the two windows and of the shade in the window of the door. These houses are relatively more dissimilar than the elght houses of the other set (F1g. 3a) whlch differ only with respect to number and degree of curvature of the scallopea bottoms of the shades in the two windows. The smoke from all elght rises vertically from the chimneys and the bottoms of the shades of the windows in the doors are all stralght linea.

The hairs and the smoking chimneys, the eyes and scalloped bottoms of the shades of the windows, and the mouths and scalloped bottoms of the shades of the doors have the same locations. Therefore, receptor-orienting responses to critical features of the sets of faces and houses of comparable similarity were expected to be equivalent. Any preexperimentally acquired names aroused by critical features of the faces, however, were expected to be almost entirely different than those aroused by critical features of the houses. And these features of the faces and houses as well as the over-all characterlstics of the faces and houses are 
sufficiently dissinllar so that nonsense syllable responses were not expected to generalize from houses to faces or from faces to houses.

Nonsense syllables.--The six nonsense syllables used were selected from among those of Mandler's (1955) I1st which have high assoclative frequencles (association values). Huv (as in hover), naz (as in lizarene), and baw (as in bawd) were the mediating responses and cey (rhymes with say), dit (a.s in aitto), and gos (as in gogpel) were the terminating responses.

Apporatus.--The apparatus consisted of a vertical panel In which a small w1ndow (5 1n. $x 3$ in.) had been cut. Behind and on both sides of the window were guides to correctly position the $3 \times 6$ in. plastic cards on which the stimuli appeared. When the plastic card was dropped between the guides at the top it slid into position to 111 the window and the bottom of the card tripped a microswitch which activated a time delay relay set for $3 \mathrm{sec}$. At the end of the 3 sec. Interval a bulb on the front of the apparatus 11ghted to signal the end of the anticipation interval.

\section{Procedure}

The same sequence of training and transfer experiences was administered to each of the eight groups. During the training phase, So were familiarized with the mediating responses before those responses were conditioned to the initiating st1mul1 of Patterns $\underline{A}$ and $\underline{B}$ or of Patterns $\underline{C}$ and $\underline{D}$. 
The S 8 were then familiarized with the terminating responses of the transfer task before they began the task of associating those reponses with the initiating stimuli.

Within this common equence of experiences, however, the eight groups differed in three ways. F1rst, four of the Groups had simllar initieting stimuli and the other four had dissimilar intiating stimuli. Second, each of these halves was further divided into two groups, which were assigned to Pattern A and Pattern 트, and two other groups, which were assigned to Pattern $\underline{G}$ and Pattern $\underline{D}$. Each of these pairs of groups was then dividea into an experimental group, for which the initiating stimuli were the same for both training and transfer phases, and into a control group, for which the inftiatine stimuli of the training phase did not resemble those of the transfer phase. The experimental Eroups were those for which the arrangements of the troining and transfer tasks were des1 end D. In contrast, the arrangements for the control groups were designed to assure facilitation due to wam up and receptor-orlenting responses, while precluding the presence of the mediating responses and stimuli necessary to realize the four potterns. The controls, then, were groups in which meàlating responses and stimuli were presumakly absent. In order to counterbalance for any differences due to experiences with face stimuli or with house stimul1, half of the Ss of each of the four groups under the experimental 
condltion had faces for both transfer and training phases, and the other half of each group had houses for both training and trangfer phases. Under the control condition, half of the Is of each of the four groups had faces for the training phase and houses for the transfer phase, whlle the other half of each group had houses for training and faces for transfer. Thus, within each of the elght groups, there were two subGroups whlch were counterbalanced for posslble diferences due to faces or houses.

within these subgroups, each pattern was assigned equalIy often to the four stimuli of esoh set with subscripts 1 , $2,3,4$ and to the four stimull of each set with subscripts 5 , $6,7,8(\mathrm{F1E}, 2)$. Mhus, assignment of the patterns to one or the other of these subsets of the sets of faces and houses was al so counterbalanced.

Faniliarization with mediating responses.-Familiarization troining waส introduced to assure that Ss pronounced the syllables unformly. Also, such training was expected to reduce extra-11st responses to the inltiating stimull. Finally, since familiarization involved leaming the syllables, So who might have difficulty in mastering the syllables could be ldent1f'led and el1minated.

Fam1liarization training began by $E$ teling each $S$ that he was to say some short syllables in the same way that E. sa1d the syllables. The $\mathbf{S}$ was also told to try to memorize the syllables so that when asked by $\underline{E}$ to do so, he would be 
able to recite the syllables to E. Each of the three syllables was then presented three t1mes, once within three successive three-trial blocks. Their order within blocks was random. On each trial E sald the syllable after which $\underline{S}$ pronounced 1t. If $\underline{\mathrm{S}}$ mispronounced the syllable, E corrected him and asked him to say the syllable again. At the end of nine trials E asked $\underline{S}$ to name the syllables. Those who were able to remember and pronounce the syllables correctiy then started the training task. Those who were unable to remember and pronounce the syllables correctly were given six additional trials, two with each syllable. No $\underline{S}$ was discarded for fallure to remember and pronounce the syllables correctly after these additional trials.

Training.--The mediating responses of Patterns $\underline{A}$ and $\underline{B}$ or of Patterns $\underline{C}$ and $\underline{D}$ were acquired by the paired-associates technique. Each trial conslsted of the presentation of one of the face or house stimuli for three sec., after which the bulb lighted and E sald the syllable for the response which $\underline{S}$ was to associate with that stimulus. Whether or not $\underline{S}$ had anticlpated correctly he was instructed to say the syllable after $E$. When $\underline{S}$ had done so, the stimulus was removed and the next stimulus was presented. The time interval between successive trials was not controlled; it averaged about 3 sec.

In order to better equalize the strengths of responses to each of the initiating stimuli, the method of adjusted 
learning was employed. When the correct anticlpations for particular stimuli had occurred on three successive trials, those stimuli were removed. After all three responses reached this criterion, their stimuli were reintroduced and presented unt1l the correct response for each st1mulus occurred one more time.

Since each of the elght different stimuli of the four sets of similar or dissimilar face or house stimull was printed on four different colors of paper, within each set there were 32 figure-color combinations. Each of the eight different faces or houses of a set appeared once within successive blocks of elght trials each. Within these blocks their order was random. The particular color on which each face or house appeared within each block of trials was determined randomly, within the restriction that each figure-color combination appeared once within successive blocks of 32 trials each.

Fam1liarization w1 th terminating responses.--The instructions and procedures for familiarization with the term1nating responses were 1dentical to those for familiarization w1 th mediating responses. However, the three nonsense syllables were those which were to be the terminating responses of the transfer task. No $\underline{\text { S }}$ was eliminated for fallure to learn these responses.

Transfer.--All Ss were fiven 32 trials to learn common or different terminating responses to the initiating stimuli. 
These st1mulus-response relationships were also learned by the palred-associates method. Fach of the elght faces or elght houses of each set of stimuli appeared once within successive blocks of elght trials. Nithin blocks their order was random. The particular color on which each face or house appeared with in each block of trlals was determined randomly within the constraint that each of the 32 flgure-color comb1nations appeared once within the 32 trials. Subjects

The 9 s were 96 chllaren from the Erving School Union (Loverett, Shutesbury, Wendell, New Salem, Erving) drawn from among those between the ages of elght and 11 in grades two through 81x. The elght group of 12 Sg each and, within these groups, subgruops for face or house stimuli of $81 \times 3 \mathrm{~s}$ each to which the children were asslgned, were equated as nearly as possible for sex and for means and ranges of ages and IQ's. To ald in equating for $I_{Q}$, all ohllaren with IQ's of less than 90 or more than 125 were excluded. (Ages, IQ's, and numbers of boys and girls in each group and subgroup are given in the Append $1 x$.) 


\section{RESULTS}

\section{Training}

The data of the training phase provided information about acquisition of the comon or discriminative mediating responses to the sets of $81 \mathrm{milar}$ and dissimilar face and to the sets of similar and dissimilar house stimuli. Of inter est were the questions of whether the sets of similar face and similar house stimuli were of equal difficulty, and whether the sets of dissimilar face and dissimilar house otimull were of equal difflculty. Also of concern was whether learning rates and pre-transfer experiences were equal both for the four groups assigned to Patterns $\underline{A}$ and $\underline{B}$ or to Patterns $\underline{C}$ and $\underline{D}$ under experimental or control cond1t1ons which responded to s1milar stimul1, and for the four corresponding groups which responded to dissimilar initiating stimuli.

The columns for "faces," "houses" and "faces and houses" and the rows for "E," "C," and "E and C" conditions of the upper half of Table 1 present means and standard deviations of numbers of trials to reach the criterion of three successlve correct anticipations of the common mediating response for Patterns $A$ and $\underline{C}$. The further breaidowns for these patterns show means and standard deviations for combinations of similar or dissimilar faces or houses, and subsequent assignment to experimental or control conditions. Presented in the 


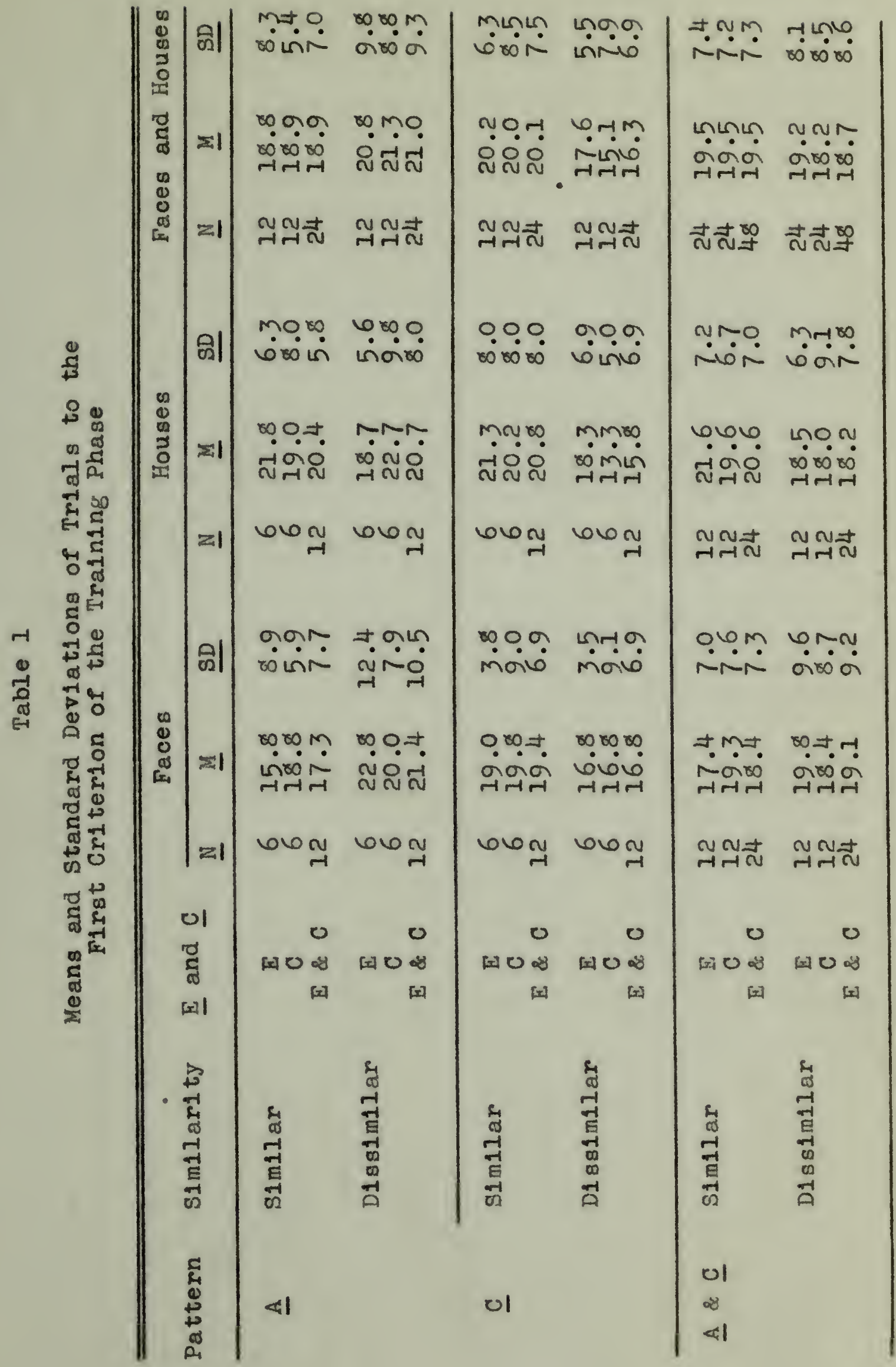




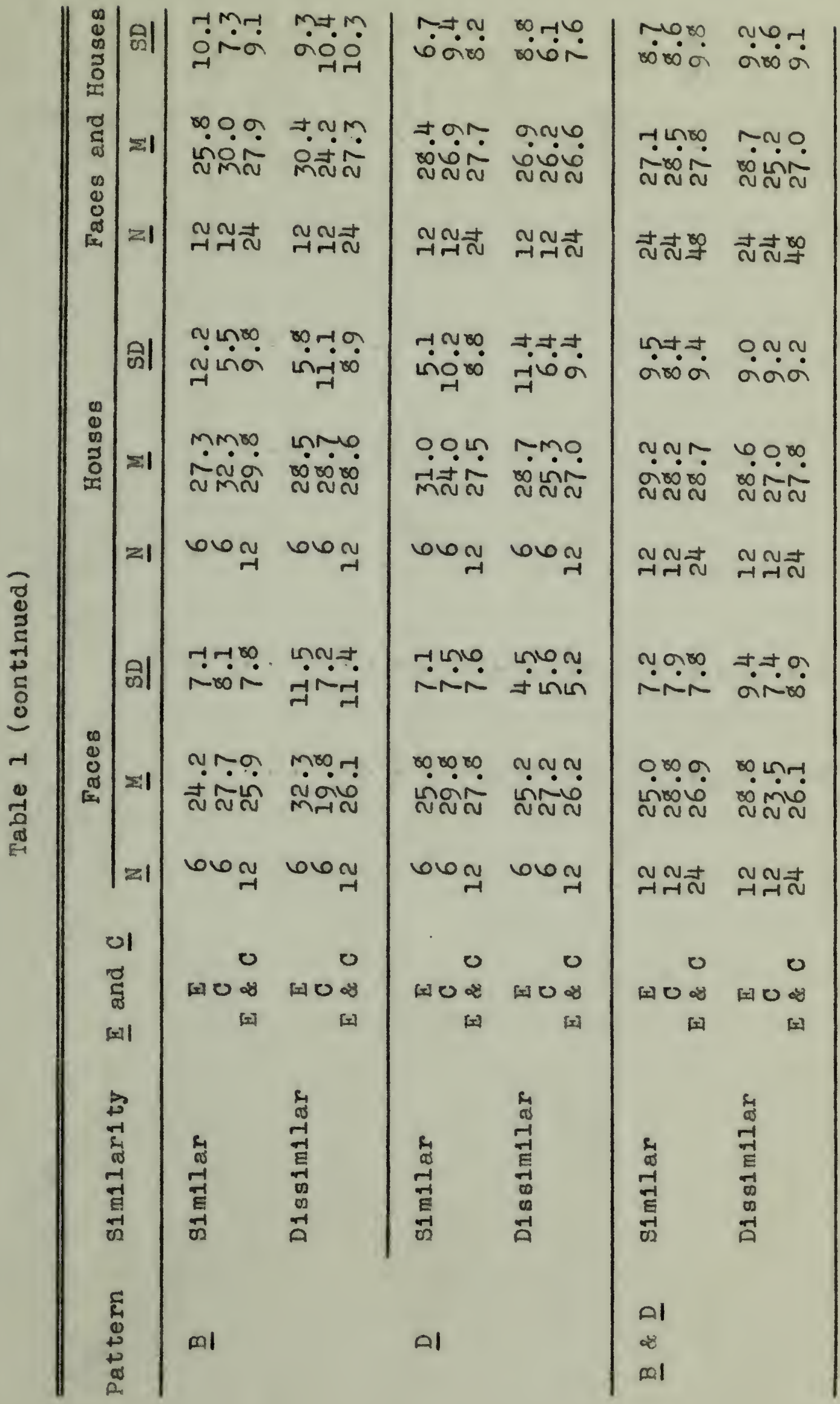


lower half of Table $I$ are comparable means and stanaard dev1ations of numbers of trials to learn both of the discriminative mediating responses of Patterns $\underline{B}$ and $D$ to the criterion of three successive correct anticipations. Since the task was not mastered unt1l both responses had reached criterion, these means are based on sums of trials to criterion for both discriminative responses.

The second orlterion of one further correct anticipation of the common mediating response and of each discriminative mediating response was achleved by most $\underline{S}$ on the flrst trial on which the stimuli for each of the se responses were reintroduced. At most only three furtres trials, including the criterion trial, were required. Thus, these scores aded little or no information to that provided by number of trials to the criterion of three successive correct responses. For this reason, and because of marked skewness of the distributions, trials to the second criterion were not analyzed further. 2

The slgniflcanoe of differences among these means was assessed by the analysis of varlance summarized in Table 2. The factors which had been varied systematically were face or house stimul1, their similerity or disimilarity, and

2. Numbers of trials for each $S$ to learn the common mediating response and both discriminative mediating responses to the first and second criterion are reproduced in the Append1x. Also given are the numbers of correct common and discriminative terminating responses during the transfer phase. 
Table 2

Analysis of Variance of Trials to

Criterion during the Training Phase

\begin{tabular}{|c|c|c|c|c|}
\hline Source & df & $\underline{S S}$. & $\underline{M S}$ & $\underline{F}$ \\
\hline $\begin{array}{l}\text { Between Ss } \\
\text { Faces-Houses (B) } \\
\text { S1m1lar-Dissimilar (C) } \\
\text { AB-CD (D) } \\
\text { Experimental-Control (E) } \\
\text { BC } \\
\text { BD } \\
B E \\
C D \\
C E \\
D E \\
B C D \\
B C E \\
B D E \\
C D E \\
B C D E \\
\text { error (b) }\end{array}$ & $\begin{array}{r}95 \\
1 \\
1 \\
1 \\
1 \\
1 \\
1 \\
1 \\
1 \\
1 \\
1 \\
1 \\
1 \\
1 \\
1 \\
1 \\
80\end{array}$ & $\begin{array}{r}10715.87 \\
68.88 \\
30.88 \\
59.63 \\
27.76 \\
30.88 \\
47.01 \\
12.50 \\
125.13 \\
97.75 \\
9.63 \\
12.50 \\
131.68 \\
277.92 \\
53.13 \\
84.01 \\
9646.58\end{array}$ & $\begin{array}{r}68.88 \\
30.88 \\
59.63 \\
27.76 \\
30.88 \\
47.01 \\
12.50 \\
125.13 \\
97.75 \\
9.63 \\
12.50 \\
131.68 \\
277.92 \\
53.13 \\
84.01 \\
120.58\end{array}$ & $\begin{array}{c}- \\
\overline{-} \\
\overline{-} \\
\overline{-} \\
\overline{-} \\
1.04 \\
\overline{-} \\
\overline{-} \\
1.09 \\
2.30 \\
\overline{-}\end{array}$ \\
\hline $\begin{array}{l}\text { Within } \frac{S s}{} \\
\text { Common-Discriminative (A) } \\
A B \\
A C \\
A D \\
A E \\
A B C \\
A B D \\
A B E \\
A C D \\
A C E \\
A D E \\
A B C D \\
A B C E \\
A B D E \\
\text { ACDE } \\
\text { ABCDE } \\
\text { error } \quad \text { (w) } \\
\text { Total }\end{array}$ & $\begin{array}{r}96 \\
1 \\
1 \\
1 \\
1 \\
1 \\
1 \\
1 \\
1 \\
1 \\
1 \\
1 \\
1 \\
1 \\
1 \\
1 \\
1 \\
80 \\
191\end{array}$ & $\begin{array}{r}6277.50 \\
3291.80 \\
13.54 \\
.01 \\
19.38 \\
3 . .25 \\
26.26 \\
11.51 \\
2.77 \\
86.67 \\
45.05 \\
7.13 \\
.87 \\
9.61 \\
94.91 \\
148.75 \\
168.15 \\
2347.84 \\
16993.37\end{array}$ & $\begin{array}{r}3291.80 \\
13.54 \\
.01 \\
19.38 \\
3.25 \\
26.26 \\
11.51 \\
2.77 \\
86.67 \\
45.05 \\
7.13 \\
.87 \\
9.61 \\
94.91 \\
148.75 \\
168.15 \\
29.35\end{array}$ & $\begin{array}{c}112.16 \\
\overline{-} \\
- \\
\overline{-} \\
\overline{-} \\
- \\
2.96 \\
1.53 \\
\overline{-} \\
- \\
3.23 \\
5.07^{*} \\
5.73^{*}\end{array}$ \\
\hline
\end{tabular}

Significant at the .05 level

signiflcant at the .001 level 
acquisition of comon mediating or alscriminative mediating responses. Though Is were pre-assigned to Patterns $\underline{A}$ and $\underline{P}$ or to Patterns $\underline{C}$ and $\underline{D}$ under experimental or control cond1tions, these were not systematic factors until the transfer phase. Each - leamed both a cominon mediating response and two alscriminative mealatine responses; this factor was a "w1thin Sg" effect wh1le the other four factors were "between 3s" effects.

only three E's were signiflcant. The p1rst of these 1nd lcated that, disreearaing the other four factors, the conmon medating response was learned faster than the discriminative mediating responees.

For Patterns $A$ and $\underline{B}$ under the experimental condition, the comblnetions of common mediatine response-similar stimul1, comion mediatinf response-dissimilar stimuli, discriminat1ve mediating responses-similar stimuli, and discriminat1ve medating responses-dissimilar st1muli had means whose rank-order was $1,2,3,4$, respectively. For Patterns $\underline{C}$ and $\underline{D}$

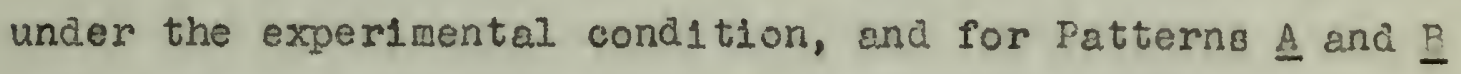
and patterns $\underline{C}$ and $\underline{D}$, both under the control condition, the comparable rank-orders were, respectively, $2,1,4,3 ; 1,2,3,4$; and $1,2,4,3$. The differences in these rank-orders were the probable basis of the algnificant ACDE interaction. These same differences in rank-orders, as suggested by the nonsigniflcant $E$ for the ratio of the $A C D E$ and $A B C D E$ inter actions, were probably the relationshlp smong means reflected 
in the significant $A B C D E$ interaction. Transfer

The performance measure of the transfer phase was the number of correct responses for the 16 trials in which the common terminating responses of Patterns $\underline{A}$ and $\underline{D}$ were correct and the number of correct responses for the $16 \mathrm{trials}$ in which one or the other of the discriminative terminating responses of Patterns $\underline{B}$ and $\underline{C}$ was correct. Means and standard deviations of numbers of these responses are shown in Table 3 for combinations of: (a) Patterns $\underline{A}, \underline{B}, \underline{C}$, and $\underline{D}$, (b) faces or houses, (c) similar or dissimilar stimuli each (d) under experimental or control conditions. Differences among these means might have been due to any one or more of these factors, elther alone or in combination, and also to assignment to Patterns $\underline{A}$ and $\underline{B}$ or to Patterns $\underline{C}$ and $\underline{D}, \in 1$ ther alone or in combination with the other factors.

Because Patterns $A$ and $\underline{B}$ were administered to half of the $\underline{S} s$ and Patterng $\underline{C}$ and $D$ were administered to the other half, the analysis of variance used to assess the signif1cance of the effects of the five factors was somewhat unusual. The "between Ss" sources of variance in which all Ss were involved were: (a) faces or houses, (b) similar or dissimilar stimuli, (c) experimental or control conditions, and (d) assignment to Patterns $\underline{A}$ and $\underline{B}$ or to Patterns $\underline{C}$ and $\underline{D}$.

For $\underline{S}$ assigned to Patterns $\underline{A}$ and $\underline{B}$, the "w1thin $\underline{S} 8$ " sources of variance were Pattern $A$ or Pattern $\underline{B}$ and the 


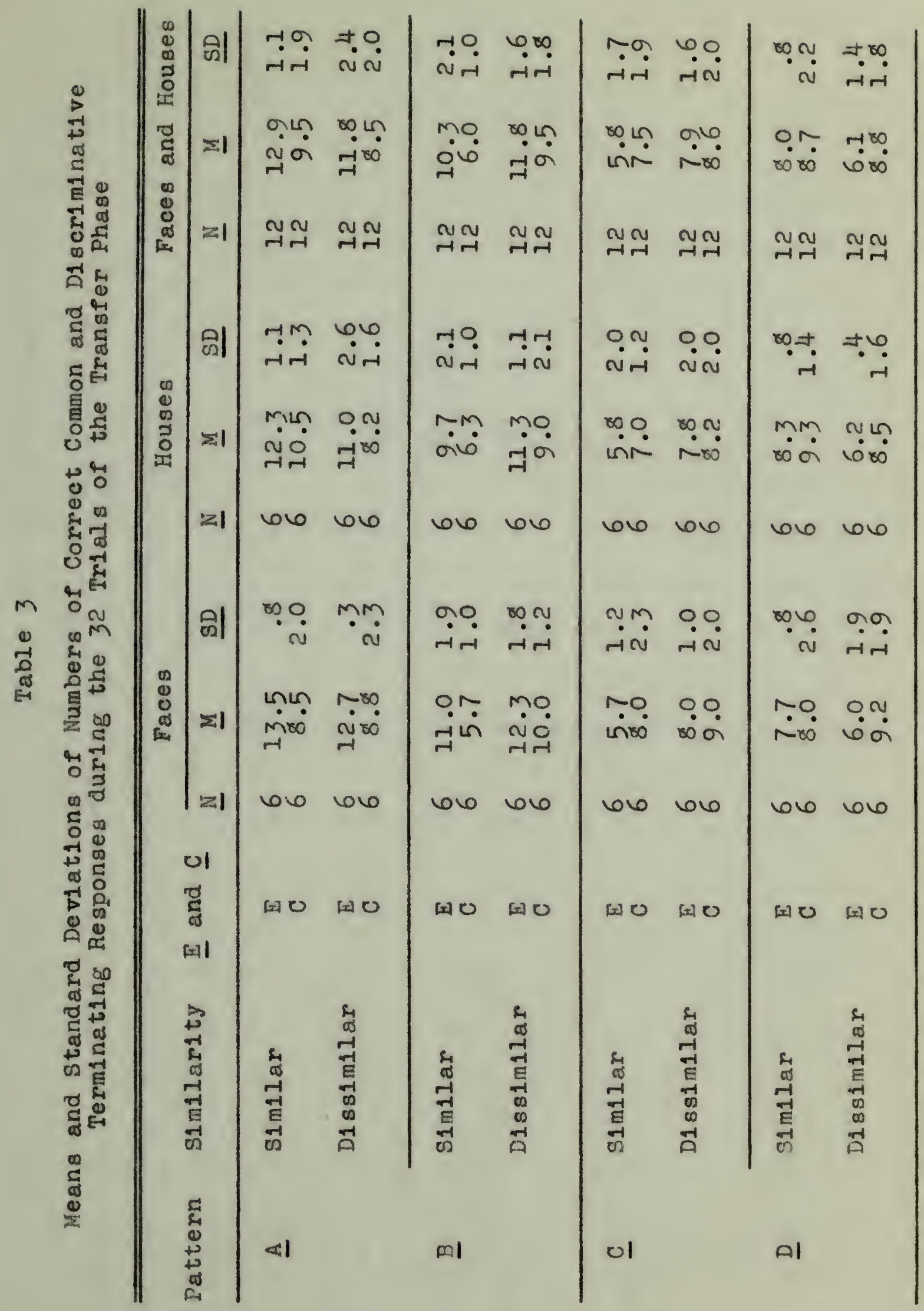


interactions of this factor with faces or houses, similar or dissimilar stimuli, and experimental or control conditions. Each of the latter three factors and their interactions w th ezch other were "between Ss" sources, but now for only half of the $\underline{5} 8$. For $\underline{S}$ assigned to Patterns $\underline{C}$ and $\underline{D}$, these patterns and their interactions with the other factors were the sources of "vathin $\$ s "$ effects; the other factors were "between $\underline{S} s "$ sources.

Differences among the means for these conditions both separately and in combination are onalyzed and described in four steps. Considered flrst are the "between Ss" effects in which all Ss were involved. "Petween $\underline{S} s$ " and "within S effects for Patterns $\underline{A}$ and $\underline{B}$ are then exam1ned, after whlch attention is given to these effects for Patterns $C$ and $D$. After analyses of varlance for patterns $\underline{A}, \underline{B}, \underline{C}$, and $\underline{D}$ separately are presentod, Pattern A is compared with Pattern D and Pattern B 18 compared with Pattern $\underline{\text {. }}$.

"Between Ss" for all Ss.--For the "between Ss" effects In which all Ss were involved, Fs slgniflcant at beyond the .05 level were obtained for similar or dissimilar stinuli, for assignment to Patterns $\underline{A}$ and $\underline{B}$ or to Patterns $\underline{C}$ and $\underline{D}$, and for experimental or control conditions (Table 4). The for similar or dissimilar stimul1 was due to more correct responses with similar atimuli than with dissimilar stimuli. More correct responses were made with Patterns $A$ and $\underline{B}$ than w1th Patterns $\underline{C}$ and $\underline{D}$. F1nally, there were more correct 
Table 4

Analys1s of Variance of Correct Responses during the 32 Trials of the Transfer Phase

\begin{tabular}{|c|c|c|c|c|}
\hline Source & df & $\underline{S} \underline{S}$ & MS & $\underline{F}$ \\
\hline $\begin{array}{l}\text { Between } 5 s^{a} \\
\text { Faces-Houses (B) } \\
\text { S1milar-Dissimilar (C) } \\
A B-C D \text { (D) } \\
\text { Experimental-Control (E) } \\
B C \\
B D \\
B E \\
C D \\
C E \\
D E \\
B C D \\
B C E \\
B D E \\
C D E \\
B C D E \\
\text { error (b) }\end{array}$ & $\begin{array}{r}95 \\
1 \\
1 \\
1 \\
1 \\
1 \\
1 \\
1 \\
1 \\
1 \\
1 \\
1 \\
1 \\
1 \\
1 \\
1 \\
80\end{array}$ & $\begin{array}{r}951.70 \\
3.79 \\
14.63 \\
273.13 \\
43.13 \\
9.63 \\
2.13 \\
3.26 \\
1.50 \\
7.13 \\
277.92 \\
1.27 \\
5.01 \\
13.13 \\
.89 \\
1.23 \\
293.92\end{array}$ & $\begin{array}{r}3.79 \\
14.63 \\
273.13 \\
43.13 \\
9.63 \\
2.13 \\
3.26 \\
1.50 \\
7.13 \\
277.92 \\
1.27 \\
5.01 \\
13.13 \\
.89 \\
1.23 \\
3.67\end{array}$ & $\begin{array}{c}1.03 \\
3.99^{*} \\
74.42^{* * * *} \\
11.75^{* *} \\
2.62 \\
- \\
- \\
1.94 \\
75.73^{\text {** }} \\
- \\
1.37 \\
3.58 \\
- \\
-\end{array}$ \\
\hline $\begin{array}{l}\text { Between Ss } \\
\text { Faces-Houses (B') } \\
\text { Slmilar-Dissimilar (C') } \\
\text { Exper1mental-Control (E') } \\
B^{\prime} C^{\prime} \\
B^{\prime} E^{\prime} \\
E^{\prime} C^{\prime} \\
B^{\prime} E^{\prime} C^{\prime} \\
\text { error (b) }\end{array}$ & $\begin{array}{r}47 \\
1 \\
1 \\
1 \\
1 \\
1 \\
1 \\
1 \\
40\end{array}$ & $\begin{array}{r}451.24 \\
6.51 \\
12.76 \\
270.01 \\
7.60 \\
14.26 \\
6.51 \\
6.51 \\
127.08\end{array}$ & $\begin{array}{r}6.51 \\
12.76 \\
270.01 \\
7.60 \\
14.26 \\
6.51 \\
6.51 \\
3.18\end{array}$ & $\begin{array}{c}2.05 \\
4.01 \\
84.91 \\
2.39 \\
4.48 \\
2.05 \\
2.05 \\
-\end{array}$ \\
\hline $\begin{array}{l}\text { Whin thin } S^{3} s \\
A^{\prime} B\left(\bar{A}^{\prime}\right) \\
A^{\prime} B^{\prime} \\
A^{\prime} C^{\prime} \\
A^{\prime} E^{\prime} \\
A^{\prime} B^{\prime} C^{\prime} \\
A^{\prime} B^{\prime} E^{\prime} \\
A^{\prime} C^{\prime} E^{\prime} \\
A^{\prime} B^{\prime} C^{\prime} E^{\prime} \\
\text { error (W) } \\
\text { Total }\end{array}$ & $\begin{array}{r}48 \\
1 \\
1 \\
1 \\
1 \\
1 \\
1 \\
1 \\
1 \\
40 \\
95\end{array}$ & $\begin{array}{r}269.50 \\
38.76 \\
.51 \\
75.26 \\
.01 \\
1.26 \\
1.76 \\
5.51 \\
.01 \\
146.42 \\
720.74\end{array}$ & $\begin{array}{r}38.76 \\
.51 \\
75.26 \\
.01 \\
1.26 \\
1.76 \\
5.51 \\
.01 \\
3.66\end{array}$ & $\begin{array}{c}10.59 \text { ** } \\
- \\
20.56 \text { ** } \\
\overline{-} \\
\overline{-} \\
1.59 \\
=\end{array}$ \\
\hline
\end{tabular}


Table 4 (continued)

\begin{tabular}{|c|c|c|c|c|}
\hline Source & 起 & SS & MS & $\underline{-}$ \\
\hline $\begin{array}{l}\text { Eetween } 3 \mathrm{~s}^{\mathrm{C}} \\
\text { Faces-Houses (B") } \\
\text { S1m1lar-Dissimilar (C") } \\
\text { Exper1mental-Control (E") } \\
\text { B"C" } \\
\text { B"E" } \\
\text { E"C" } \\
\text { B"E"C" } \\
\text { error (b) }\end{array}$ & $\begin{array}{r}47 \\
1 \\
1 \\
1 \\
1 \\
1 \\
1 \\
1 \\
40\end{array}$ & $\begin{array}{r}227.33 \\
.04 \\
3.38 \\
51.04 \\
2.67 \\
1.50 \\
1.50 \\
166.38 \\
1662\end{array}$ & $\begin{array}{r}.04 \\
3.38 \\
51.04 \\
2.67 \\
1.50 \\
1.50 \\
. .38 \\
4.17\end{array}$ & $\begin{array}{c}.01 \\
.82 \\
12.24 \% * \\
.64 \\
.36 \\
.36 \\
.09 \\
-\end{array}$ \\
\hline 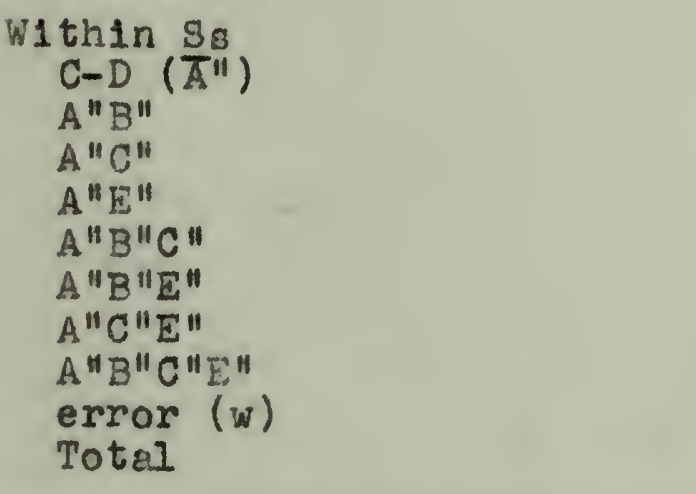 & $\begin{array}{r}48 \\
1 \\
1 \\
1 \\
1 \\
1 \\
1 \\
1 \\
1 \\
40 \\
95\end{array}$ & $\begin{array}{r}188.00 \\
5.04 \\
4.17 \\
37.50 \\
1.50 \\
2.04 \\
1.04 \\
15.04 \\
1.50 \\
120.17 \\
415.33\end{array}$ & $\begin{array}{r}5.04 \\
4.17 \\
37.50 \\
1.50 \\
2.04 \\
1.04 \\
15.04 \\
1.50 \\
3.00\end{array}$ & $\begin{array}{c}1.68 \\
1.39 \\
12.50^{+1+4} \\
.50 \\
.68 \\
.35 \\
5.01 * \\
.50 \\
-\end{array}$ \\
\hline
\end{tabular}

* Significant at the .05 level

* Significant at the .01 leveI

a. For a.l Ss

b. For $S_{s}$ as̄signed to Patterns $A$ and $B$

c. For $\underline{\bar{S}} \mathrm{~g}$ assigned to Patterns $\underline{\underline{C}}$ and $\bar{D}$ 
responses under the experimental condition than under the control condition. Only the interaction of assignment to Patterns $\underline{A}$ and $\underline{B}$ or to Patterns $\underline{C}$ and $\underline{D}$ with experimental or control conditions was s1gnificant. Under the control condition there were 8.38 correct responses with Patterns $A$ and $\underline{B}$ and 8.40 correct responses with Patterns $\underline{C}$ and $D$. While these means were signiflcantly lower (tg of 6.09 and 6.05 ,

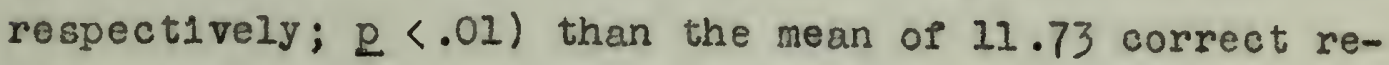
sponses vith Patterns $\underline{A}$ and $\underline{B}$ under the experimental cond1tion, they were signiflcantly higher (ts of 2.62 and 2.65; ps (.01) than the mean of 6.94 correct responses for patterns C and $D$ under the experimental condition. Since there was a greater increase with Patterns $\underline{A}$ and $\underline{B}$ than there was a decrease With Patterns $\underline{\mathrm{C}}$ and $\underline{D}$, the positive transfer with the former patterns was greater than the negat1ve transfer with the latter patterns.

Patterns $\mathrm{A}$ and $\mathrm{B}$-- The comnon terminating response of Pattern $A$ was correct more erequently than the discriminative terminating responses of Pattern $\underline{B}(\underline{F}=10.59 ; \underline{p}$ <.01). Further, signiflcantiy more correct responses occurred for Fatterns $\underline{A}$ and $B$ together under the experimental condition than under the control conaltion. Nelther faces or houses nor similar or dissimilar stimuli had signiflcant effects, though the $F$ for the latter comparison was just short of the .05 level.

Under the control condition, the means of 8.25 correct 
responses for face $s$ timuli and of 8.50 correct responses for house etimuli were essentlally equivalent. Under the experimental condition there was an increase of 4.13 to a mean of $12.38(\underline{t}=5.66 ; \underline{p}(.01)$ correct responses for face st1mul1 and an increase of 2.58 to a mean of 11.08 ( $\underline{t}=3.53 ; \underline{p}<.01$ ) correct responses for house stimul1. The difference between these two increases was sufficlent to produce an interaction ( $\left.B^{\prime} E^{\prime \prime}\right)$ of the two Pactors significant at the .05 level. With Pattern $\underline{A}$, the mean of 11.21 correct common terminatIng responses to similar st1mul1 was larger, but not $81 \mathrm{~g}-$ nificantly larger $(\underline{t}=1.39 ; \underline{\mathrm{L}} \doteq .15)$, than the mean of 10.17 for such responses to a1ssimilar stimul1. W1th Fattern $\underline{B}$, the mean of 8.17 correct discriminative terminating responses with similar stimull was algniflcantly smaller than the mean of 10.67 for such responses to a1ssimilar st1mul1 $(\underline{t}=3.33$; $\mathrm{p}<.01)$. Eecause of this reversal in relative numbers of correct responses to similar and dissimilar stimul1 with Pattern $\underline{A}$ and w1 th Pattern $\underline{B}$, the interaction of these two factors ( $\left.A^{\prime} C^{\prime}\right)$ was highly signifloant.

Patterns $\cong$ anú D.-- 1 1gn1 f1cantly fewer correct responses occurred under the experimental condition than under the control condition $(\underline{F}=12.24 ; \underline{p}(.01)$. The elgnificant interaction ( $A^{\prime \prime} C$ ") of similar or dissimilar stimuli with Pattern C or Pattern D was apparently brought about by two opposing trends. For Pattern $\underline{C}$, the mean of 8.25 correct alscriminative terminating responses to dissimilar stimuli 


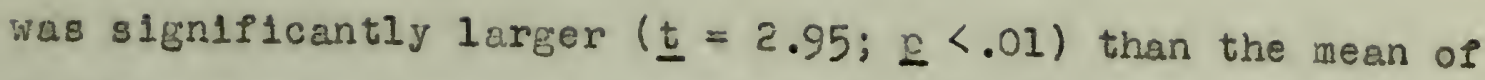
6.63 to similar stimuli. For Pattorn $\underline{D}$, fewer correct common terminating responses occurred with dissimilar stimuli $(\underline{M}=7.46)$ than with similar stimul1 $(M=8.33)$. The $\underline{t}$ of 1.58, however, was not slgnificent.

Also significant was the triple interaction (A"C"E") of similar or dissimilar stimuli, Pattern $\underline{C}$ or Pattern $\underline{D}$, and experimental or control conditions. Th1s effect can be attributed to differences in the differences between experimental and control conditions for the four combinations of similar or dissimilar stimui1 with Fattern $\underline{C}$ or Pattern $\underline{D}$. Specifically, for combinations of similar stimuli-pattern $\underline{C}$,

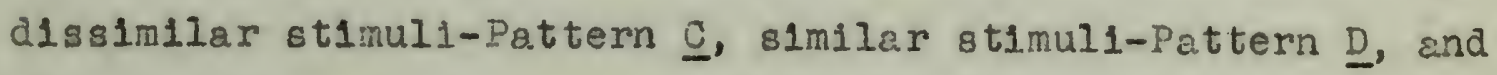
dissimilar st1mul1-Pattem $\underline{D}$, the deferences between the pairs of means for experimental and control conditions, in the alrection of larger means for the control condition, were, respectively, $2.75,0.66,0.67$, and 2.65 . The f1rst $(\underline{t}=3.57)$ and last $(\underline{t}=3.44)$ of the se differences were significant at the .01 level; the secona $(\underline{t}=0.86)$ and third $(\underline{t}=0.87)$ were not significant.

Patterns A, B, C, and D separately.--The sets of face and house stimul1 were essentially equivalent (Table 5). Accordingly, this factor was not included in snalyses of varlance for Patterns $\underline{A}, \underline{B}, \underline{C}$, and $\underline{D}$ separately, for each of which the sources of variation were similar or dissimilar stimuli, experimental or control conditions, and the 
interaction of these two variables. For Pattern $\underline{A}$, the mean of 12.92 correct common teminating responses for similar stimuli under the experimental condition was greater $(\underline{t}=4.17 ; \mathrm{g}<.01)$ than the mean of 9.50 for similar st1mul1 under the control condition. The means for alssimiler stimull under experimental sna control conditions were 11.33 and $8.50(\underline{t}=4.06 ; \underline{p}<.01)$, respectively. While significantly more $(\underline{t}=4.12 ; p<.01)$ correct responses were made under the experimental condition $(\underline{M}=12.38)$ than under the control condition $(\mu=9.00)$, the mean of correct reeponses to similar stimul1 ( $M=11.21$ ) was not significantly greater $(\underline{t}=1.28 ; p=.20)$ than that for correct responses to digsimilar stimuli $(\underline{M}=10.16)$. The interaction of these two variables was also not significant.

For Pattern E, Elgnificantly more correct discriminative terminating responses occurred under the experimental condition $(M=21.08)$ than under the control condition $(\underline{M}=7.75)$. An $E$ of $14.15(\underline{2}<.01)$ indicated that signis1cantly more correct responses occurred with dissimilar stimul1 $(M=10.67)$ than w1th similar st1mul1 $(M=8.17)$. The means for similar and dissimilar stimuli under the experimental conaition were 10.33 and $11.83(\underline{t}=1.68 ; \underline{p}=.20)$, respectively, while the corresponding means under the control condition were 6.00 and $9.50(\underline{t}=3.93 ; \mathrm{g}<.01)$. Al though the difference of 4.33 between means for similar stimuli under experimental and control conditions was greater 
$(\underline{t}=4.86 ; p<.01)$ than the corresponding alfference of 2.33 for a1so1milar stimuli ( $\underline{t}=2.62 ; \underline{2} \doteq .02)$, the interaction was not significant.

For Pattern $\underline{C}$, slgniflcantly more correct alscriminative terminating responses were made under the control condition $(M=8.04)$ than under the experimental condition $(M=6.88)$. Also, significantly more correct responses occurred with dissimilar stimul1 $(\underline{M}=8.25)$ than with similar stimul1 $(\underline{M}=6.62)$. The means for similar and disimiler stimuli under the experimental condition were 5.75 and 7.92 ( $\underline{t}=2.78 ; \underline{p}<.01)$, respectively, while the corresponalng means under the control condition were 7.50 and 8.58 ( $\underline{t}=1.38 ; \underline{\underline{L}}=.20$ ). However, the difference between these differences was not sufficient to produce a significant interaction.

The mean of 8.00 correct common terminating responses for similer stimuli under the experimental condition of Pattern D was 1088 than the nean of 8.67 for the slmilar stimul1 unaer the control condition $(\underline{t}=0.90 ; \underline{\underline{p}} \doteq .40)$. With dissimilar st1mul.1, the means were 6.08 under the experimental condition and $\$ .83$ under the control condition $(\underline{t}=3.72 ; \mathrm{L}<.01)$. Though the aifference between these two differences was large, the $\mathrm{F}$ for the interaction fell just short of the .05 level. D1sregarding similarity of stimuli, the mean of 8.75 for the control condition was significantly Ereater than the mean of 7.04 for the experimental condition. While more correct responses occurred with siallar stimuli 
$(\underline{M}=8.34)$ than with aissimilar stimuli $(\underline{M}=7.46)$, the difference was not significant; nor was the interaction signi11cant.

Pattern $A$ and Pattern D.--In the analysis of variance for Pattern A and Pattern D, for both of which there was a common teminating response, the Fs for experimental or control conditions, for similar or dissimilar stimuli, and for assignment to Pattern $\mathbb{A}$ or Pattern $D$ were significant at or beyond the .05 level (Table 6). The $F$ for experimental or control conditions was due to a difference of 3.38 in favor of the experimental condition for Pattern A whlch was greater than the difference of 1.54 in favor of the control condition for Pattern $D$. Thus the mean of 9.71 under the experimental condition exceeded that of 8.88 under the control condition. The other Fs were due to occurrence of more correct responses with similar $(M=9.78)$ than with dissimilar stimuli $(\underline{M}=8.81)$, and of more correct responses with Pattern $\underline{A}$ $(\underline{M}=10.69)$ than with Pattern $\underline{D}(\underline{M}=7.90)$. The main source of the interaction of Pattern A w1th Pattern D under experimental or control conditions was the greater number of correct responses under the experimental condition $(M=12.38)$ than under the control condition $(\underline{M}=9.00)$ for Pattern $\underline{A}$ and the smaller number of correct responses under the experimental condition $(\underline{M}=7.04)$ than under the control condition $(\underline{M}=8.75)$ for Pattern $\underline{D}$.

$\underline{\text { Pattern }} \underline{\underline{B}}$ and Pattern $\underline{\text { C. }}$--Patterns $\underline{\underline{B}}$ and $\underline{\mathrm{C}}$ both involved 


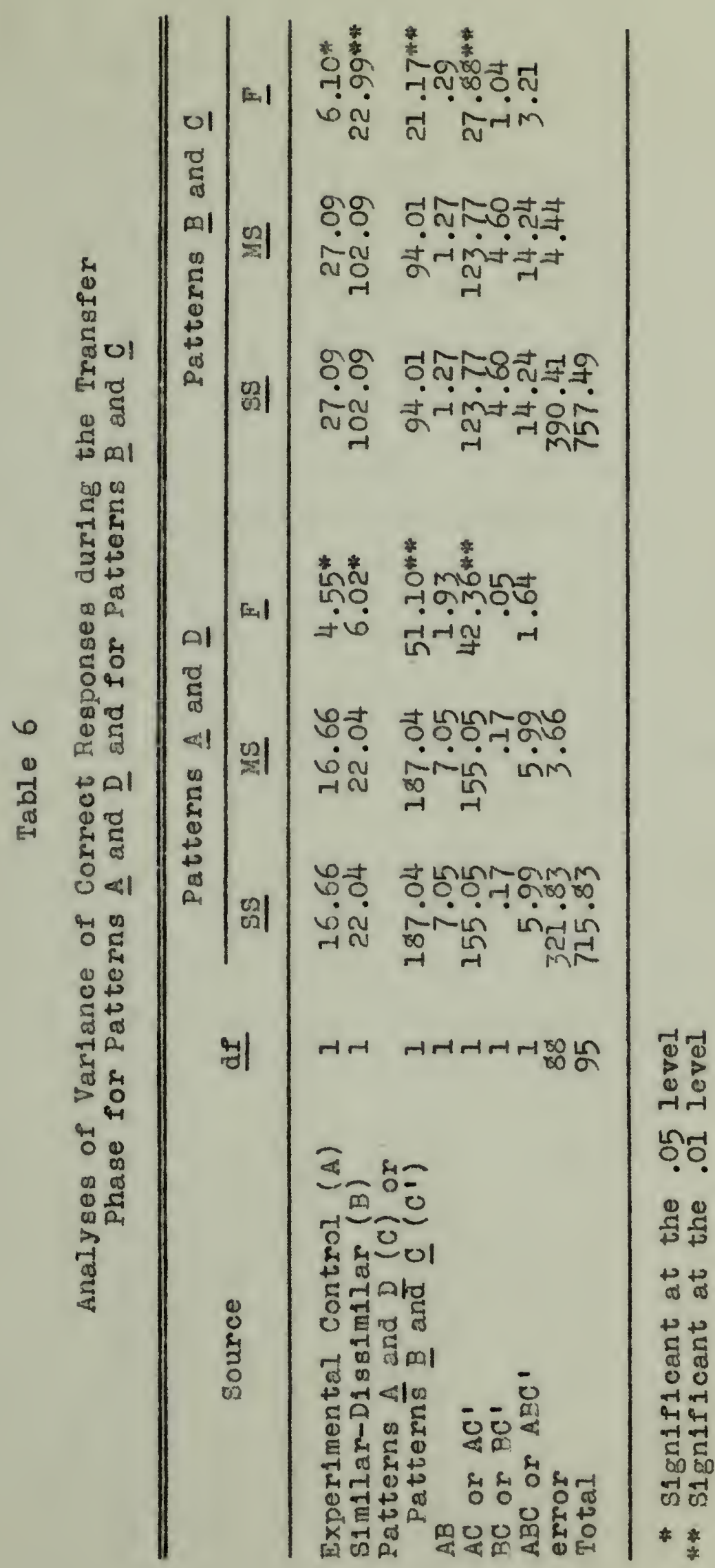


discriminative terminating responses (Table 6). The Es of the analysis of varlance indicated that significantly more correct responses had occurred for Pattern $\underline{B}(\underline{M}=9.42)$ than for Pattern $\underline{C}(\underline{M}=7.46)$. Also, disregarding other factors, there were more correct responses under the experimentel condition $(\underline{M}=8.98)$ than under the control condition $(M=7.92)$ and with dissimilar stimuli $(\underline{M}=9.46)$ than with similar

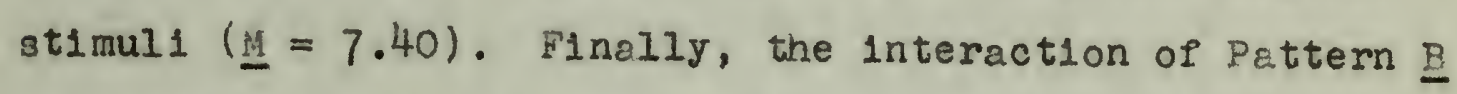
or Pattern $\underline{\mathrm{C}}$ under experimental or control conditions was significant. Since the means under the control condition were nearly equal, this interaction was due to more correct responses under the experimental condition $(M=11.08)$ than under the control condition $(\underline{M}=7.75)$ for Pattern $\underline{B}$ and fewer correct responses under the experimental condition $(\underline{M}=6.88)$ than under the control condition $(M=8.08)$ for Pattern $\underline{\mathrm{C}}$. 


\section{Discussion}

Statistical analysis of the training data indicated that, regardless of other conditions, the common mediating response was acquired more rapidly than discriminative mediating responses. This was consistent w1 th Lacey's (1956) finding of slower learning as the number of responses increased.

While two interactions were significant, the relationshlps among the means rellected in those interactions were not of a form whlch might have accounted for differences among conditions and combinations of conditions obtained during the transfer phase. On the whole, therefore, differences among the groups with respect to training were nonsignificant or unimportant. Of greater importance was the finding that the sets of similar faces and of similar houses did not differ in difficulty; this was also the case for the sets of disimilar faces and of dissimilar houses.

The over-all analysis of varlance of numbers of correct responses during the transfer phase was of a form which could be treated more convenlently and more meaningfully by beginning with findings for all four patterns combined and proceeding to those for each pattern separately. The sets of prealctions, however, were developed in the opposite direction, and it is this direction which will be followed in comparisons of predicted with observed relationships. 
Consldered first are comparisons of predicted with observed relationships for simliar and dissimilar inltiating st1muli under experimental or control conditions for Patterns A, $\underline{3}, \underline{C}$, and $\underline{D}$ separately. Then alscussed are hypotheses and results 1nvolving Patterns $\underline{A}$ and $\underline{B}$ and those involving Patterns $\underline{C}$ and $\underline{D}$. After predictions and results involving Patterns $A$ and $B$ and involving Patterns $\underline{C}$ and $D$ are considered, Plndings with respect to all 16 combinations are treated. Patterns $\stackrel{A}{=}, \stackrel{B}{=}$, and $\underset{D}{D}$ separately.--For Pattern $\underline{A}$, in which acquisition of a common mediating response was followed by acquisition of a common teminating response, more correct terminating responses were expected under experimental than under control conditions and with slmilar than with dissim1lar stimul1. Both of these expected differences occurred, but only the former was statistically significant.

The interaction of these two variables was not s1gnif1cant. There was no evidence, therefore, for the suggestion that the effects of a common mediating stimulus on acquisition of a common terminating response might be different for dissimilar than for similar initiating stimuli. However, as noted, neither the rationale nor the emplrical grounds for th1 suggestion was compeli1ng. Further, other factors may have precluded a significant interaction. For example, the mediating stimuli may have constituted such a large part of the compounds of Inltiating and mediating stimuli that even relatively large differences in the similarity of 
initiating stimuli coula produce only relatively small, difficult-to-detect differences in simllarity of the compounds. Or, the alfferences in similarity of the similar wth respect to the dissimilar initiating stimuli may not have been sufficient to produce a significant interaction. E1ther of these factors might have also precluded a significant interaction of experimental or control conditions with slmilar or dissimilar stimuli for Patterns $\underline{B}, \underline{C}$, and $\underline{D}$.

Under the experimental condition with pattern $\underline{B}$, discriminative mediating regponses were acquired to either similar or dissimilar initiating stimul1; subsequently alscriminative teminating responses were acquired. The prealction that the presence of discriminative mediating responses and st1muli would lead to more correct discriminative terminating responses under the experimental condition was confirmed. Also confirmed was the prediction that discriminative teminating responses to dissimilar stimuli would be learned faster than such responses to slmilar stimuli. However, the relatively greater facilitation under the experimental condition than under the control condition with similar than with dissimilar inltiating stimul1 which had been anticipated was not obtalned. Two possible reasons for this nonsignificant interaction were noted in connection with the nonsignificant interaction for Pattern A.

1th pattern $\underline{C}$, a common mediating response was learned to inltiating stlmull and then discriminative terminating 
responses were assoclated with those same stimul1. Slower acquisition rates of the terminating response were predicted under the experimental than under the control condition. Th1s prediction and the expectation of slower learning with similar than with dissimilar inftiating stimuli were both conf1rmed. Not confirmed, however, was the prediction of greater retardation under the experimental condition with disoimilar stimuli than with similar in1tiating stimuli. Again, the reasons may be those mentioned for Pattern A. The acquisition of different mediating responses with Pattern D was followed by acquisition of a common terminating response. The predicted slower learning under the experimental than under the control condition or negative transfer, as anticlpated, was obtained and the difference was statistically significant. Fewer correct responses occurred with dissimilar than with similar initiating stimuIl, but the difference was not significant. The prealction that acquisition rates with similar and dissimilar initiating stimul1 would not differ less under the experimental than under the control condition was not confirmed. In fact, the obtained relationship among the four means was opposite that predicted.

Pattern A w1th Pattern $\underline{\text { B and }}$ Pattern $\subseteq$ with Pattern D.-In addition to predictions of positive transfer for both Pattern $\underline{A}$ and Pattern $\underline{B}$ already noted, 1 was expected that the common terminating response of Pattern A would be 
mastered more raplaly than the discriralnative teminating responses of Pattern B. Predicted, also, was an interaction in the form of more correct responses with similer than with dissimilar inftiating stiauli for Pattern $\underline{A}$ and the converse for Pattern B. All three hypothees were conflrmed.

The predicted negative transfer was obtained with both Pattern $\underline{C}$ and Pattern $D$, while the comon teminating response of Pattern D was correct more often than the discriminative teminating responses of Pattern $\underline{C}$, as antic1pated, but the difference was not s1gniflcant. With Pattern C, correct responses occurred more frequently w1th dissimilar than with 31 milar stimuli, and with Pattern $D$ more correct terminating responses occurred with similar than with disimilar initiating stimuli. This was the prealcted interaction.

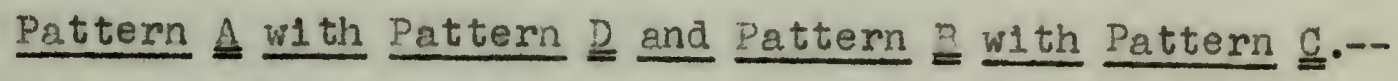
While Pattern A and Pattern D both had a common teminating regponse, Pattern 1 involved a comnon mediating response and Pattern D involved aiscrininative mediating responses. Because mediating stimuli presumably increased s1milarity of 1nitiating stimull in the former pettern and decreased such similarity in the latter pattern, positive transfer was predioted for Pattern A and negative transfer for Pattern $\underline{\text { D. }}$ The obtained significant interactions confimed this prodiction. Further, the positive transfor for Pattern 1 outwelghed the negative transfer for Pattern $D$. While 
similarity of initiating stimuli did not have significant effects for Pattern A or Pattern D separately, for the two patterns combined, signiflcantly more correct responses occurred with similar than with dissinilar initiating stimuli.

Pattern $\underline{B} 1$ involved discriminative mediting responses and Pattern $\underline{C}$ involved a common medleting response; both had discriminative terminating responses. The predictions were of better performance for Pattern $\underline{B}$ than for Pattern $\underline{C}$ with dissimilar stimuli than with similar initiating stimuli. Also expected was a slgnificant interaction based on positive transfer for Pattern $\underline{B}$ and negative transfer for Pattern $\underline{C}$. These predictions were confirmed. Also, the facllitation for Pattern B exceeded the retardation for Pattern $\underline{C}$.

All 16 combinstions.--The largest number of correct terminating resoonses, as predicted, was obtained for Pattern A with similar initiating stimuli under the experimental condition. Also, as preaicted, the smallest number of correct terminating responses occurred for Pattern $\underline{\mathrm{C}}$ with similar inltiating stimuli under the experimental condition. The remaining 14 combinations of conditions were at intermediate levels of achievement.

Against controls whlch provided for effects of warm up and receptor-orienting responses, Pattern $A$ and Pattern $B$ led to positive transfer and Pattern $\underline{C}$ and Pattern $\underline{D}$ led to negative trangfer. The nature of the medlating responses, therefore, as predicted, apparently determine whether 
acquisition of common or alscriminative terminating responses is fac1litated or retaraed.

Degree of similarity of the initiating stimuli produoed differences in the predicted direction with all four patterns. Speciflcally, more correct common terminating responses occurred with similar stimuli than with dissimilar stimuli for Patterms $\underline{A}$ and $D$ and with dissimilar than with similar stimuli for Pattems $\underline{B}$ and $\underline{C}$. Only with Patterns $\underline{B}$ and $\underline{C}$, how ever, were the differences between similar and dissimilar inftiating 6timuli slenificant. Since both of these patterns involved discriminative terminating responses, similerity of initiating stimuli may hove relatively greater effects on transfer tasks involving digcrimination than on those involving generalization.

In general, the findings support the notion that verbal mediating responses and stimull play an important role in conceptual naming. Further, these results for conceptual naming both support and extend previous findings of the importance of mediating verbal responses and stimuli in conceptual sorting. 


\section{SUMMARY}

The signiflcance of verbal mediating responses and atimul1 in conceptual naming was investigated by means of a design in which four patterns of possible relationships among Inltiating stimul1, mediating stimuli and responses, and terminating responses vere comblned with sets of similar or disolmilar initiating gtimul1. The patterns involved initiating atimuli to which $S$ s learned (a) a common mediating response and then a common terminating response (Pattern $\Lambda$ ), (b) discriminative mediating regponses and then discriminat1ve terminating responseg (Pattern B), (c) a common mediating response and then discriminative termineting responses (Pattern $\underline{C}$ ), and (d) discriminative mediating responses and then a contion teminating responge (Pattern D). The sets of similar initiating stimuli consisted of stylized line-drawings of faces or of houses which differed along but one dimension. The sets of disimilar faces or houses differed along three dimensions.

Ninety-six children of ages elght to 11 , in grades two through s1x were assigned to elght groups of $12 \mathrm{Sg}$ each, equated as nearly as possible for age, sex, and I.Q. Eoth mediating and teminating responses were three-letter nonsense syllables whlch were conditioned to the initiating stimuli by the paired-associates technique. Acquisition of mediating responses was to adjusted learning criterla; 32 
trials were allowed for acquistion of teminating responses. Under the experimental condition the face or house stimull Por both training and transfer phases were the same. For the transfer phase under the control condition the faces on houses were replaced by houses and faces, respectively.

Comparisons of experimental and control conditions indicated that the predicted positive transfer had occurred

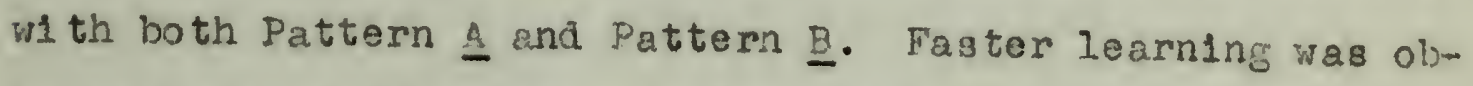
talned with similar atimuli for Pattern 1 and with dissirilar stimuli for Pattern B. Also confirmed were predictions of negative transfer under the experimental condition with Pattern $C$ and Pattern D and of faster learning with similar stimuli for Pattern $\underline{D}$ and with dissimilar stimuli for Pattern C. The common teminating response of Patterns $\mathbb{A}$ and $\underline{D}$ were acquired faster than the discriminative teminating responses of Patterns $\underline{B}$ and $\underline{C}$, respectively. On the whole, the experimental indings were interpreted as consistent with the general notion of the importance of verbal mediating responses in concept formation as well as with predictions based on the four different patterns of relationshipa amone initiat1ng st1muli, mediating responses and stimuli, and terminating responses each in combination with similar and dissimilar initiating stimuli. 


\section{References}

Arnoult, M. D. Stimulus predifferentiation: some genersl12etions and hypotheses. Psychol. Bull., 1957, 54, $339-350$.

Baum, N. H. A study in concept attainment and verbal learn1ng. Unpublished Ph.D. dissertation, Yale University, 1951.

B1rge, Jane $S$. The role of verbal responses in transfer. Unpublished master's thesis, Yale University, 1941. Carey, J. E., \& Goss, A. E. The role of verbal labeling in the conceptual sorting behavior of children. I. genet. Psychol., 1957, 90, 69-74.

Dollard, J., \& Miller, N. E. Personallty and psychotherapy. New York: McGraw-H111, 1950.

Fenn, J. D., \& Goss, A. E. The role of mediating verbal responses in the conceptual sorting behavior of normals and schizophren1cs. J. genet. Psychol., 1957, 90, 59-67. Goss, A. I. A stimulus-response analysis of the interaction of cue-producing and instrumental responses. Psychol. Rev., 1955, 62, 20-31.

Goss, A. E. Mediating verbal responses. Unpublished manuscript. Undver. of Mass., 1957.

Goss, A. E. Report on the University of Massachusetts conference on problem solving. June 19-21, 1956. Amherst, Massachusetts, 1956. 
Goss, A. E., \& Greenfeld, N. Transfer to a motor task as influenced by conditions and degree of prior discrimination training. I. exp. Pgychol., 1958, 55, 258-269. Goss, A. E., \& Moylan, M. C. Conceptual block-sorting as a function of type and degree of mastery of discriminat1ve verbal responses. J. genet. Psychol., 1958, 93 , 191-198.

Hanfman, E., \& Kasinin, J. Conceptual thinking in schizophrenia. New York: Nervous and Mental Disease Monogr., 1942 .

Heldbreder, Edna B. The attainment of concents: I. Term1nology and methodology. J. genet. Psychol., 1946, 35 , 173-189.

Helabreder, Eana B. The attainment of concepts: II. The problem. J. genet. Psychol., 1946, 35, 191-223. Hunter, G. F., \& Ranken, H. B. Mediating effects of labeling on sorting behavior and judgments of similerity. Paper read at Eastern Psychological Association, Atlant1c C1ty, March, 1956.

Jeffrey, Wendell $\mathrm{E}$. The effects of verbal and nonverbal responses in medlating an instrumental act. I. exp. Psychol., 1953, 45, 327-333.

Lacey, Harvey M. Conceptual block sorting as a function of type of assignment of verbal labels and strength of labeling responses. Unpublished M.S. thes1s, Un1versity of Massachusetts, 1956. 
Lindquist, E. F. Design and analys1s of experiments in pogychology and education. New York: Houghton-Miflin, 1953.

Mandler, George. Associative frequency and assoclative prepotency as measures of response to nonsense syllables. Amer. J. Psychol., 1955, 68, 662-665.

Mandler, $G$. Response factors in human learning. Psychol. Rev., 1954, 61, 235-244.

Miller, George A. The magical number seven, plus or minus two: some limits on our capacity for processing information. Psychol. Rev., 1956, 63, 81-97.

Murdock, Bennett B., Jr. The effects of failure and retroactive inhibition on mediated generalization. J. exp. Psychol., 1952, 44, 156-164.

Newman, Slater E. Effects of contiguity and s1milarity on the learning of concepts. I. exp. Psychol., 1956, 52, 349-353.

Osgood, C.E. Method and theory in experimental psychology. New York: Oxford Univer. Press, 1953.

Splker, C. C. Experiments with children on the hypothesis of acquired distinctiveness and equivalence of cues. Ch1la Developm., 1956, 27, 253-263. 


\section{APPENDIX}

\section{Instructions}

Familiarization w1th Mediating Responses

I want to see how well you can learn three names. They are not real names or names that you have heard before; but you should say them just l1ke other names you know. Each t1me I say one of these three names I want you to say $1 t$
just the way I do.

At the same time try to learn each name because after a whlle I'm going to ask you to tell me the three names and when I do you should be able to do so. Any questions?

Now, tell me the three names.

You forgot to tell me Let me say the names some more. Remember, say them just Iike I do and try to learn all of them because I'm going to ask you to tell me the three names again and when I do you should be able to do so.

Now, tell me the three names.

\section{Training Phase}

Now this is a game in which you have to learn the names of different pictures.

When the game begins I will drop a card in this opening and you w1Il see a colored plcture. The plcture that you w1ll see has a name. You are to try to find out its name. The name w1ll be one of the three names that you have just learned, that is, DIT, NAZ, or HUV. As soon as you think you know which of these names is the right one for the plcture, tell me that name. If the name you say 18 the right name for the pleture, I'll say, "Yes, that's right." If the name you say isn't the right name for the plcture I'Il say, "No" and tell you the right name for the plcture. After I tell you the right name, you should repeat that name. After you've seen the first picture and tried to learn its name, I'Il drop another card in the opening and you'II see another picture. The name of this pleture w1ll also be DIT, NAZ, or HUV. And you should tell me which one you think it 18. If you guess the right name, I'Il tell you that you are rlght, and 11 you guess the wrong name, I'Il say, "No, that's wrong" and tell you the right name. And then you should repeat that name. 
In all you are going to see a number of different plctures in the opening and your job will be to guess the right name for each plcture. Some will be named DIT, some w1ll be named NAZ, and some $W 111$ be named HUV. You are to learn which name goes with which plcture. To do this, as soon as I put a card in the opening you should say what you think the name of the picture $1 \mathrm{~s}$. I'Il always tell you whether you guessed the right name or the wrong name. If you say the wrong name you should repeat the right name after I tell it to you. As soon as you have any Idea about the name for each picture, say it, because if $1 t^{\prime} \mathrm{s}$ wrong I won't count it against you, and you might guess the right name. Don't feel badiy if you don't guess the names right away. It always takes people some time. However, you can learn the names of all the pictures if you try hard.

The only way you can learn each plcture's name is first to pay attention to 1 then 1 t appears in the opening and then try to guess the name of the pleture. each picture.

(If Ss seem puzzled after 3 or 4 trials stop and ask $1 f$ they have any questions.)

Familiarization with Terminating Responses

Now I want to see how well you can learn three new names. Except that the se are new names you should do like you did before: after. I say each name you should say $1 \mathrm{t}$ exactly like I do. And try to learn these new names because after a while I'm going to ask you to tell me what they are.

Remember, say the name exactly as I do. Also try to memorlze the names so that, when I ask you to tell me what they are, you can do so.

Now, tell me the three names.

You forgot to tell me Let me say the names some more. Remember, say them just Tike I do and try to learn all of them because I'm going to asis you to tell me the three names again and when I do you should be able to do so.

Now, tell me the three names. 
Transfer Phase

before.

Now we're going to play the same game that we played

When the game begins I will drop a card in this opening and you will see a colored plcture. The plcture that you W111 see has a name. You are to try to find out 1 ts name. learned, that is, 1 t will the three names that you have just you think you know whl oh of GOS, CIY, or BAN. AB soon as the plcture, tell me that the se names is the right one for right name for the picture narne. If the name you say is the If the name you say isn'te, I'II say, "Yes, that's right." I'Il say, "No" and tell you the right name for the picture, After I tell you the right the right name for the plcture. as soon as I tell it to you. picture and tried to first in the opening and this plcture will also be GOS, CEY, or BAW. And you should name I'I I ch one you think it is. If you give the right wrong name, I'l gay "No, that's wrong" and if you guess the right name. And you should repeat this and tell you the

In all you are golng to see a number of different plctures in the opening and your job will be to guess the right name for each picture. Som w1Il be named GOS, some Will be named CEY, and some $W 111$ be named BAW. You are to learn which name goes with each plcture. To do this, as soon as the door opens you should say what you think the name of the picture 1s. I'11 alvays tell you whether you guess the right name or the wrong nome. If you say the wrong name you should repeat the right name that I tell you. As soon as you have any idea always try to guess the name for each pleture you see. Say that name, because $1 f$ it's wrong I won't count $1 t$ against you, and you might guess the right name. Don't feel badly if you don't guess the nomes right away. It always takes people some time. However, you can learn the names of all the plctures if you try hard.

The only way you can leam each plcture's name is first to pay attention to 1 when 1 appears in the opening and then to try to guess the name of the pleture.

Remember, you are to try to tell me the right name for each picture. 


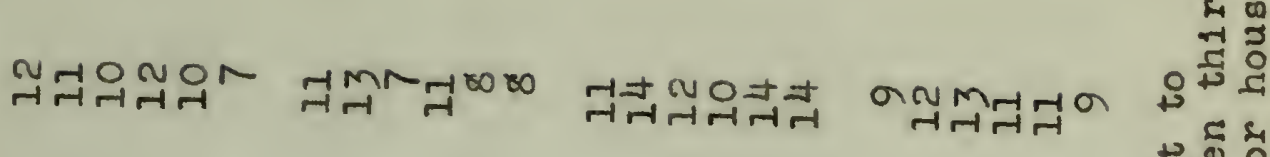

\section{LMM $\mathrm{Mm}$}

HFलmmat

ด๐LกNMM Hन्नHम

$\min _{\rightarrow-1} \infty m-$

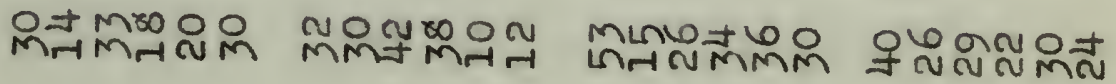

$$
\text { निम्नलन तन्ति }
$$

( )

\& -10

成范

क्ष

मै

क म

एक

$\rightarrow$ न

त)

मे

$\infty$ क

\&

0

भा 30

जन बाँ

नु न्व

टี ํํㅇ

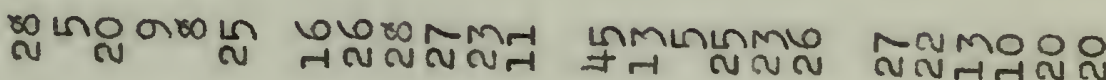

0 -

$40+$

(थ)

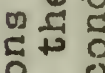

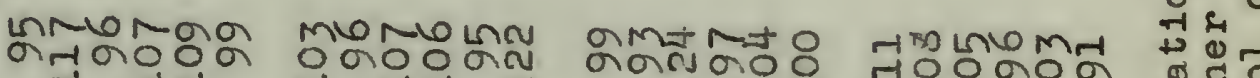

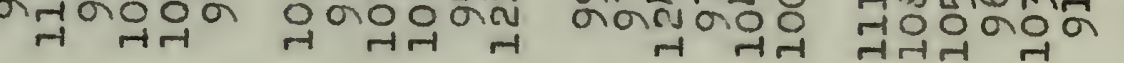

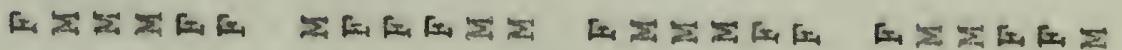

की

도

है:

8 द

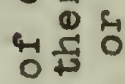

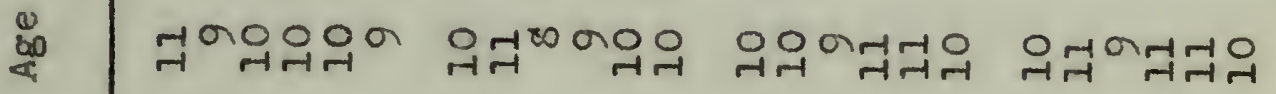

हैं क्ष

ले टี

(3) है

वling

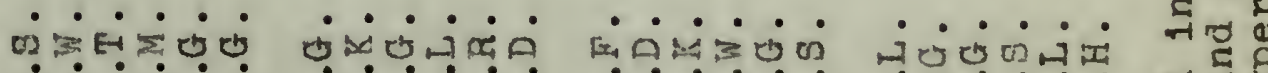

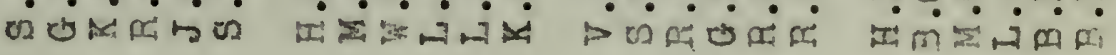

कil

סृ

ชृ

का हैं

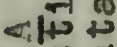

os

ट क है

क त

क्ने 0

+ है 0

का คî

릴

ह है

<it is

(4) है

\& क ज्

का क्ष

कन क ज

+ $\theta^{\circ}$ ?

๘

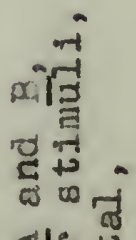

《ाद

क त

है ह

(1) त्र

क क 0

का to $0_{1} 0$

๘

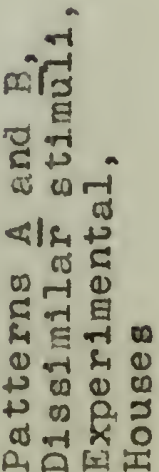

ค토도

त ब

ڤ.

मू दू

(n)

0 mis

ro

$\omega$ 起总

$0<14$

욜 吾

की द्य

द्व

प्दे

का का का 


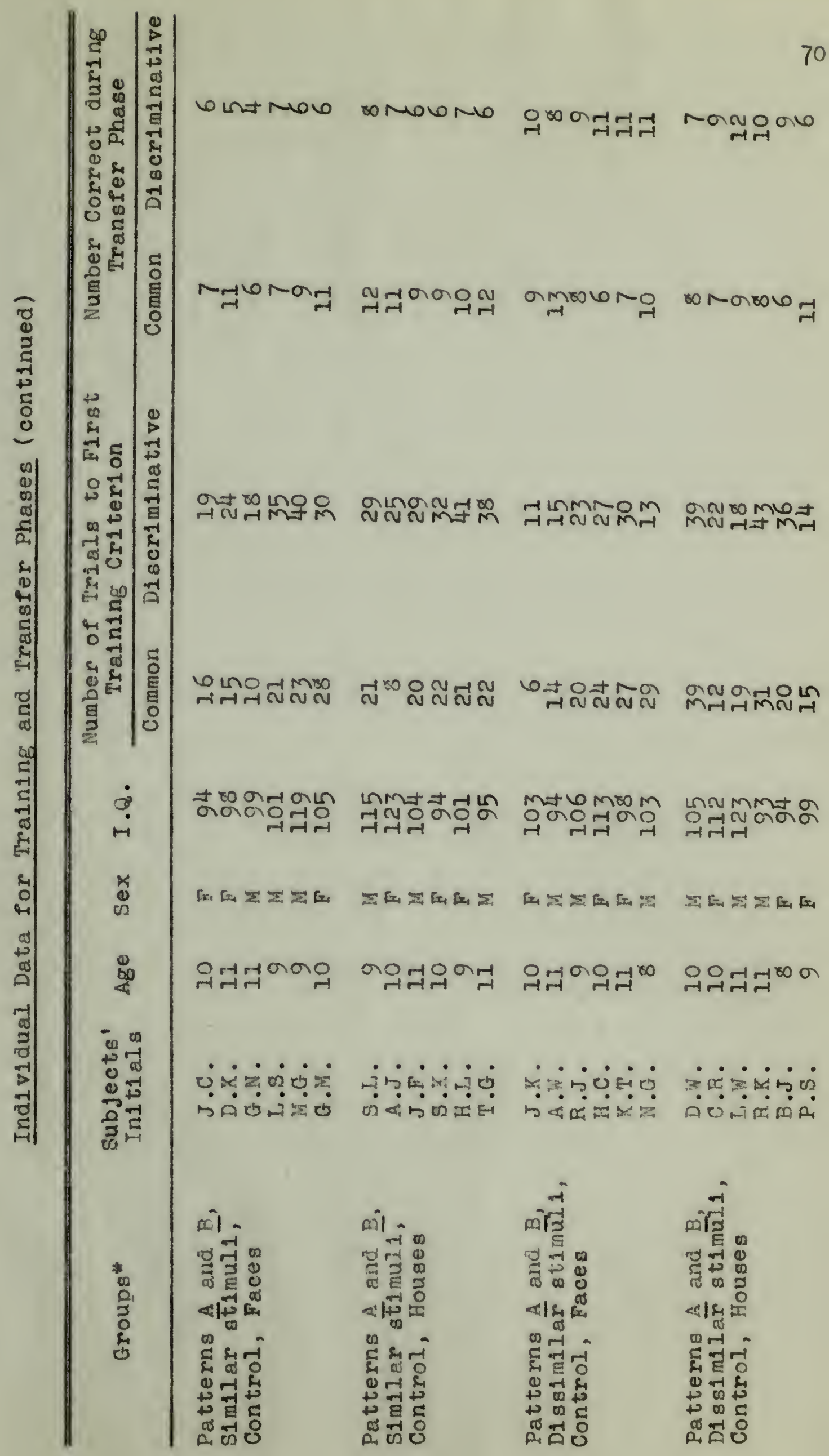




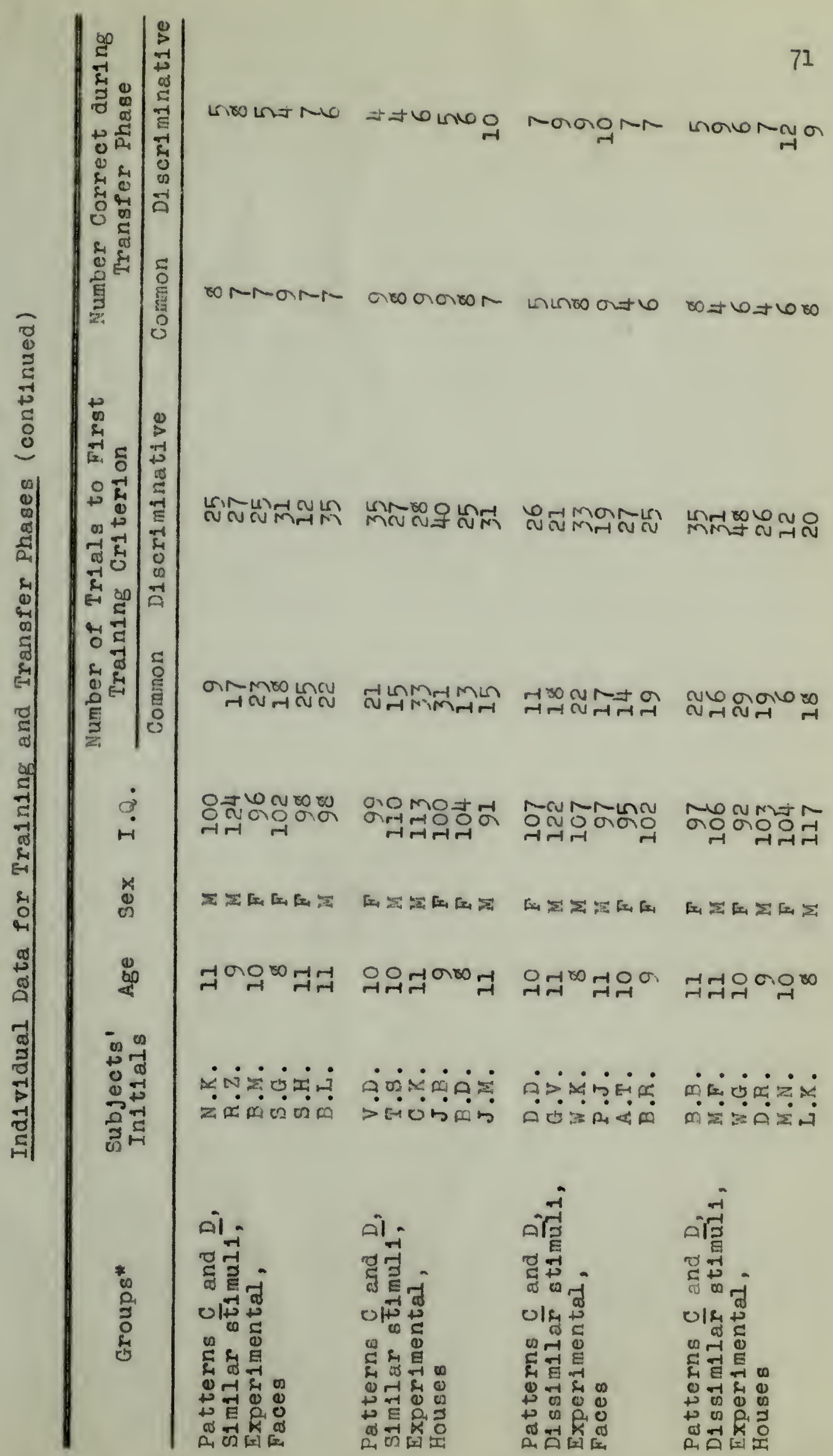




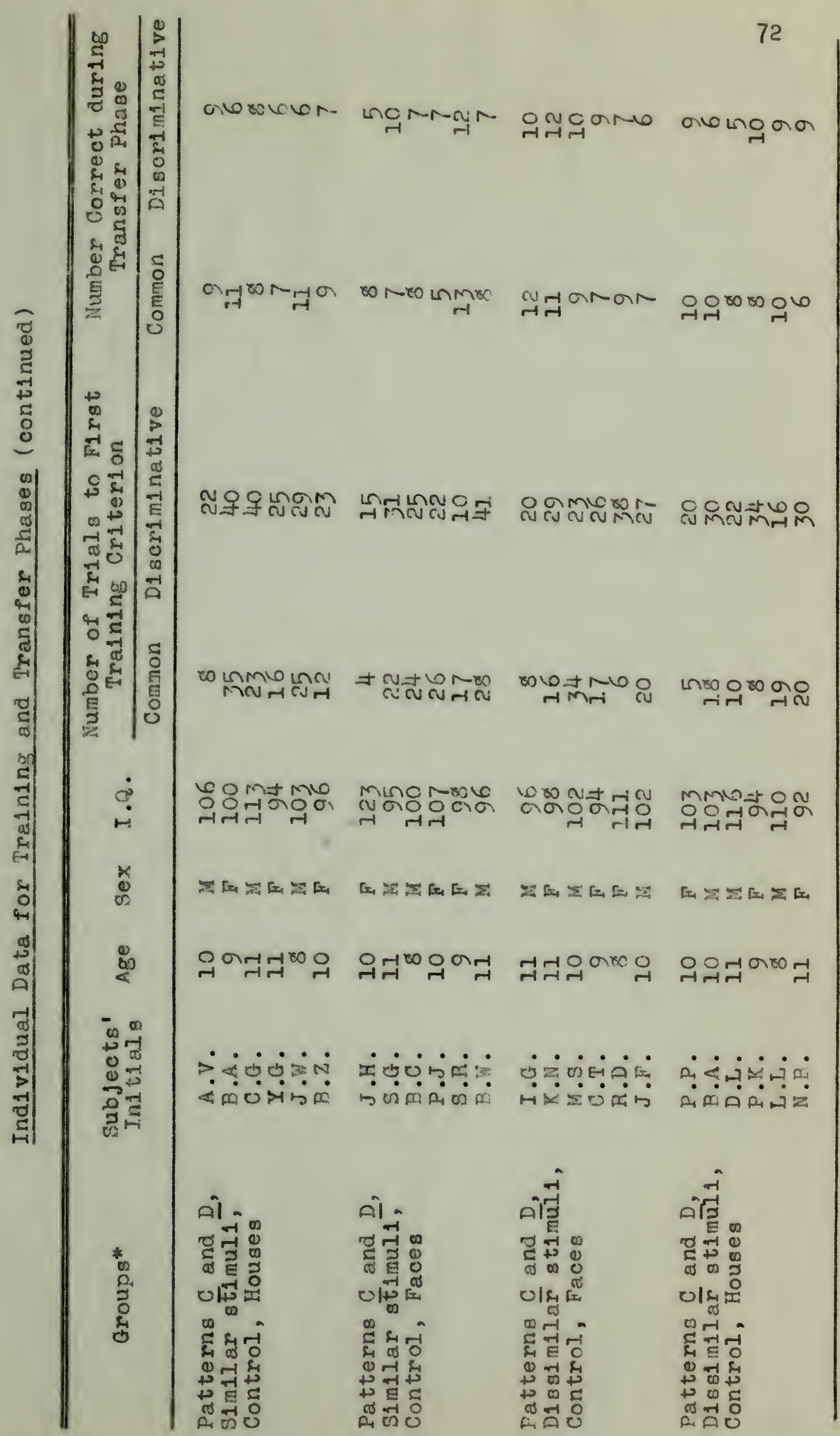


Approved by:
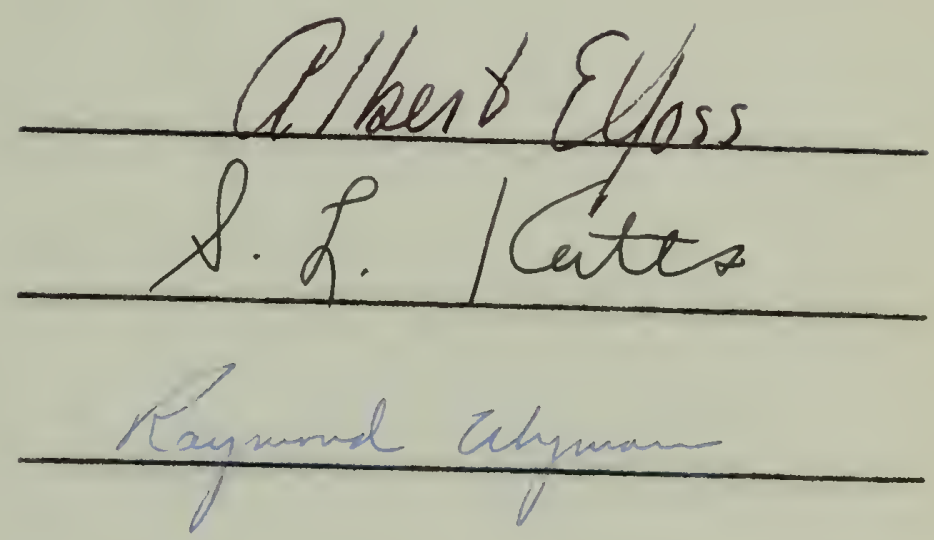

Date: Hay 27,1959 


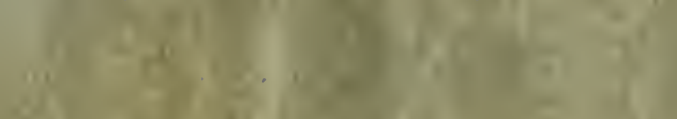

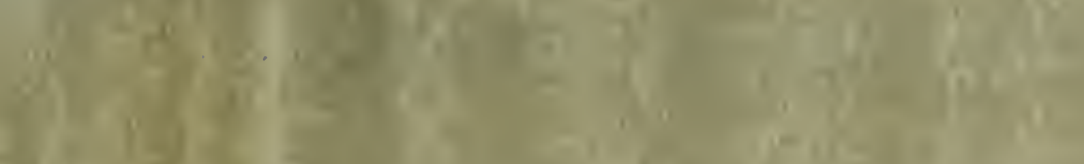

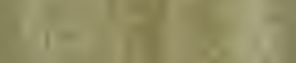

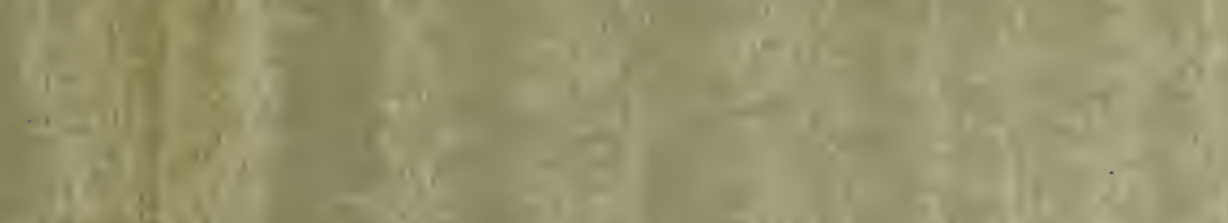

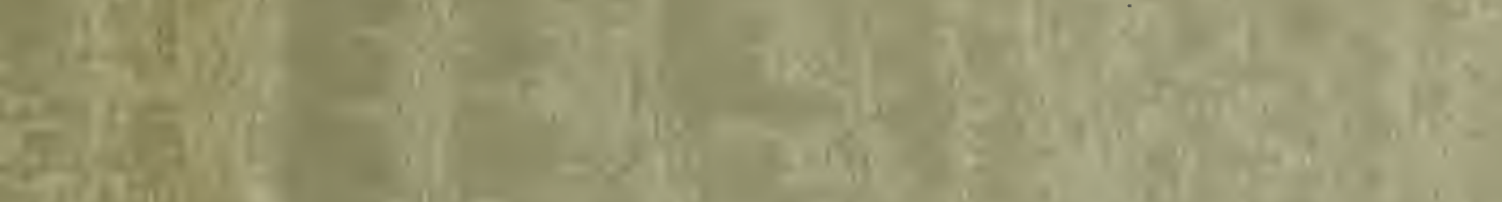
$(1)(1+1)$

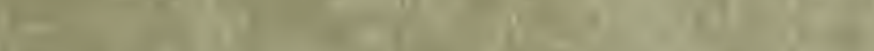

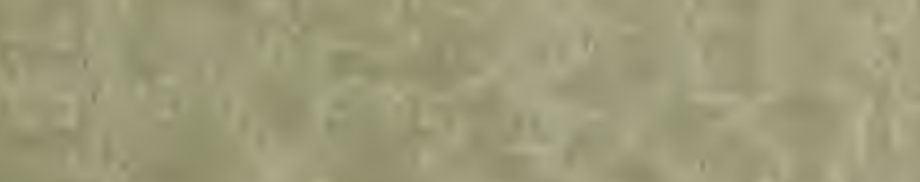

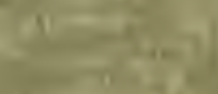

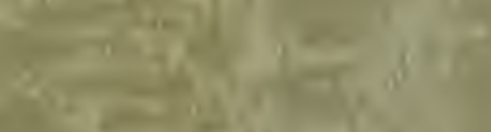

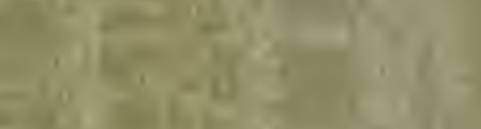

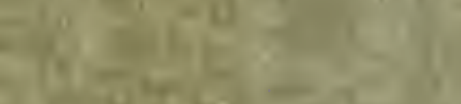

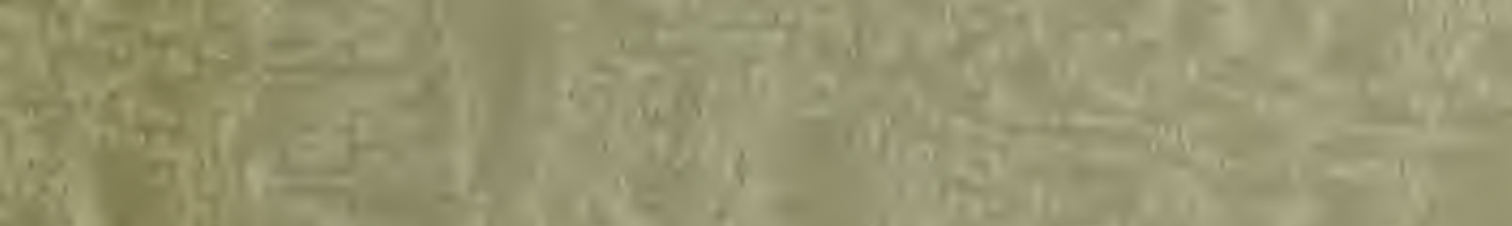

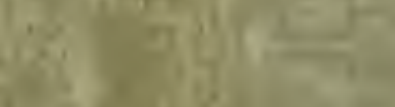

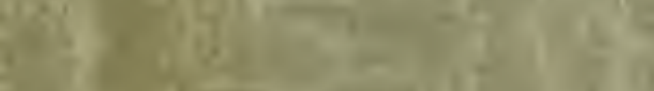

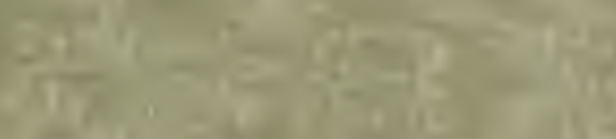

$+21$

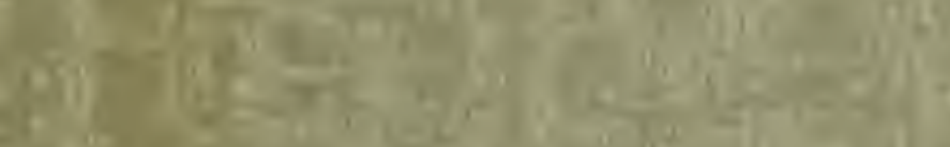

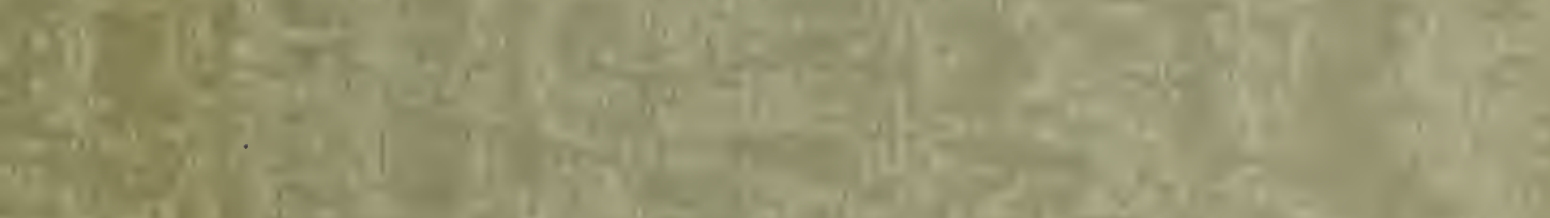

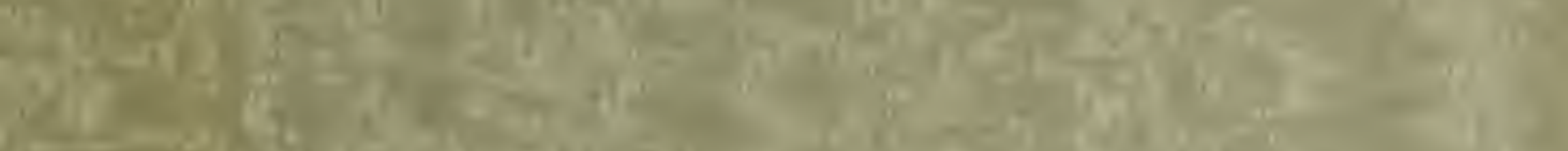

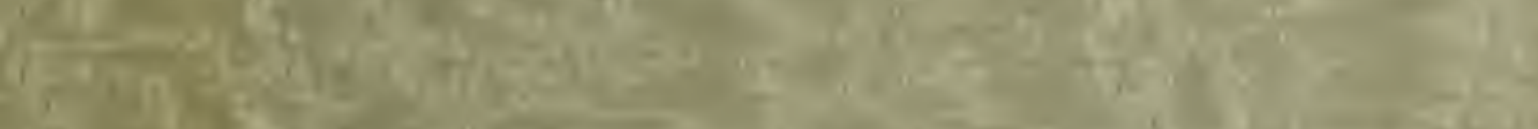

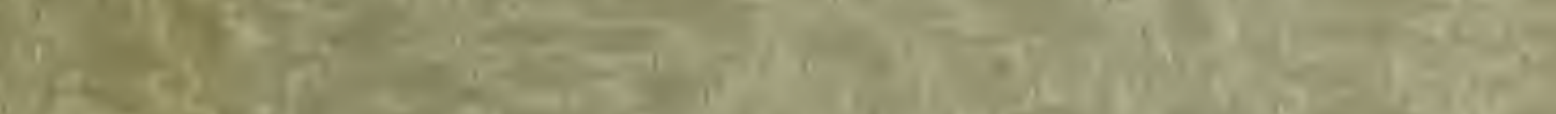

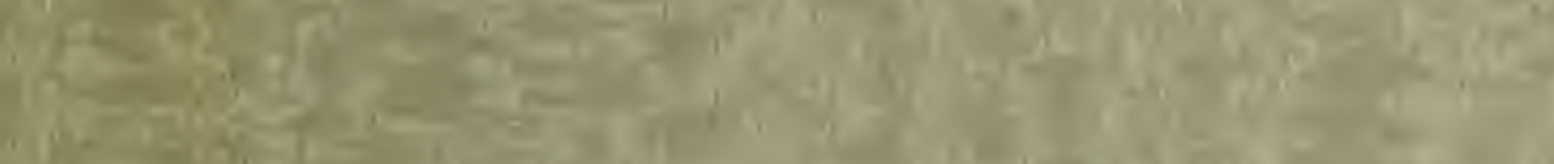

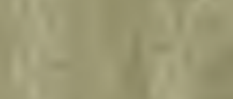
$y=2-\frac{1}{12} y$

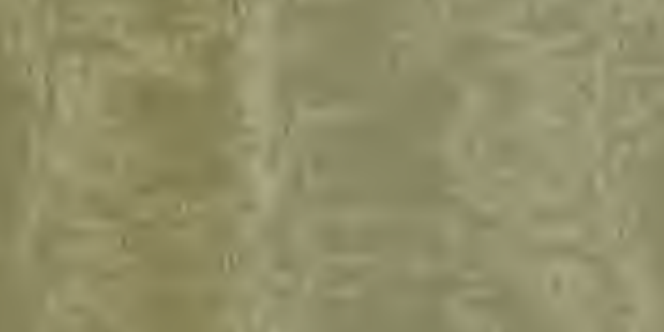
,
*. 1

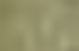
(1)
$y^{2}=\frac{1}{4}$
$-5$

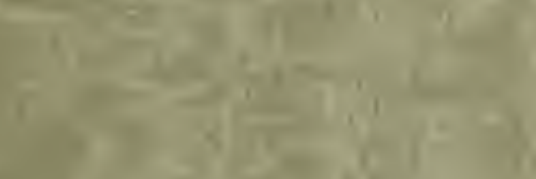

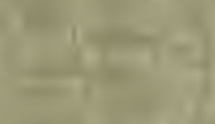

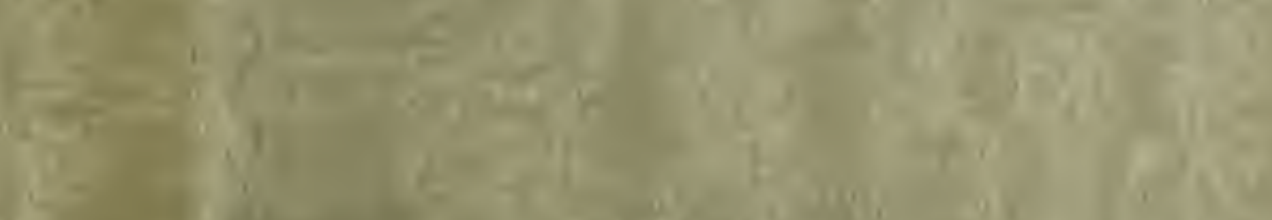

$+\frac{1}{8}$

$(x+3)$ 
